Article

\title{
The Adsorption of $\boldsymbol{n}$-Octanohydroxamate Collector on $\mathrm{Cu}$ and Fe Oxide Minerals Investigated by Static Secondary Ion Mass Spectrometry
}

\author{
Alan N. Buckley ${ }^{1, *}$, John A. Denman ${ }^{2}$ and Gregory A. Hope ${ }^{3}$ \\ 1 School of Chemistry, University of New South Wales, Sydney, NSW 2052, Australia \\ 2 Ian Wark Research Institute, University of South Australia, Mawson Lakes, SA 5046, Australia; \\ E-Mail: John.Denman@unisa.edu.au \\ 3 Queensland Micro- and Nanotechnology Centre, School of Biomolecular and Physical Sciences, \\ Griffith University, Nathan, QLD 4111, Australia; E-Mail: g.hope@griffith.edu.au \\ * Author to whom correspondence should be addressed; E-Mail: a.buckley@unsw.edu.au; \\ Tel.: +61-2-9385-4677; Fax: +61-2-9662-1697.
}

Received: 12 September 2012; in revised form: 26 November 2012 / Accepted: 4 December 2012 / Published: 10 December 2012

\begin{abstract}
The feasibility of investigating the adsorption of $n$-octanohydroxamate collector on copper and iron oxide minerals with static secondary ion mass spectrometry has been assessed. Secondary ion mass spectra were determined for abraded surfaces of air-exposed copper metal, malachite, pseudomalachite and magnetite that had been conditioned in aqueous potassium hydrogen $n$-octanohydroxamate solution, as well as for the corresponding bulk $\mathrm{Cu}^{\mathrm{II}}$ and $\mathrm{Fe}^{\mathrm{III}}$ complexes. In each case, the chemical species present at the solid/vacuum interface of a similarly prepared surface were established by X-ray photoelectron spectroscopy. The most abundant positive and negative metal-containing fragment ions identified for the bulk complexes were also found to be diagnostic secondary ions for the collector adsorbed on the oxide surfaces. The relative abundances of those diagnostic ions varied with, and could be rationalised by, the monolayer or multilayer coverage of the adsorbed collector. However, the precise mass values for the diagnostic ions were not able to corroborate the different bonding in the copper and iron hydroxamate systems that had been deduced from photoelectron and vibrational spectra. Parent secondary ions were able to provide supporting information on the co-adsorption of hydroxamic acid at each conditioned surface.
\end{abstract}

Keywords: flotation (surface chemistry); base metal minerals; reagents 


\section{Introduction}

Hydroxamate collectors are being applied increasingly in the concentration of oxide $\mathrm{Cu}$ and rare earth ores by flotation, with potassium hydrogen $n$-octanohydroxamate [1] in most common use [2]. However, there are also significant concentrations of Fe oxides such as magnetite or hematite in some of those ores, and to achieve an acceptable grade when Fe oxide gangue minerals are present, strategies to optimise the depression of Fe oxides may be required. To facilitate the development of such strategies, it is advantageous to have a detailed understanding of the interaction of hydroxamate collectors with those Fe oxides as well as with the more valuable minerals to be concentrated. The most relevant conditions for the interaction of potassium $n$-octanohydroxamate include a $\mathrm{pH}$ near 9.5, a collector concentration equivalent to a dose of up to $1 \mathrm{~kg}$ per tonne of ore, and a conditioning period less than $15 \mathrm{~min}$.

The adsorption of $n$-octanohydroxamate (as hydroximate because of deprotonation of the $\mathrm{N}$ ) on oxide $\mathrm{Cu}$ minerals at the collector's unadjusted $\mathrm{pH}$ of $\sim 9.5$ is now reasonably well understood [3], and there is strong evidence from X-ray photoelectron spectroscopy (XPS) to suggest that the interaction of this collector with $\mathrm{Fe}$ oxides [4], rare earth oxides [5], and probably many other metal oxides, is substantially different. In the case of the $\mathrm{Cu}$ oxide minerals, it is believed that the collector initially chemisorbs parallel to the mineral surface so that the two oxygen atoms of each hydroximate anion bond to a $\mathrm{Cu}$ atom in the outermost layer of the mineral and the deprotonated $\mathrm{N}$ atom interacts with a second (adjacent) $\mathrm{Cu}$ atom in the oxide surface:

$$
\mathrm{Cu}-\left[(\mathrm{OH})_{2}\right]_{\text {surf }}+\mathrm{RC}(\mathrm{O}) \mathrm{NHO}^{-} \rightarrow \mathrm{Cu}-[\mathrm{RC}(\mathrm{O}) \mathrm{NO}]_{\text {surf }}+\mathrm{OH}^{-}+\mathrm{H}_{2} \mathrm{O}
$$

With increasing collector adsorption, it is surmised that the chemisorbed hydroximate progressively adopts an essentially upright orientation so that each deprotonated $\mathrm{N}$ atom can then interact with the metal atom of a $\mathrm{Cu}$ hydroximate molecule to start a multilayer patch (Figure 1).

Figure 1. Schematic representation of $n$-octanohydroximate (blue) chemisorbed to a $\mathrm{Cu}$ atom in a $\mathrm{Cu}$ oxide surface (green) and interacting with a $\mathrm{Cu}$ hydroximate molecule (red).

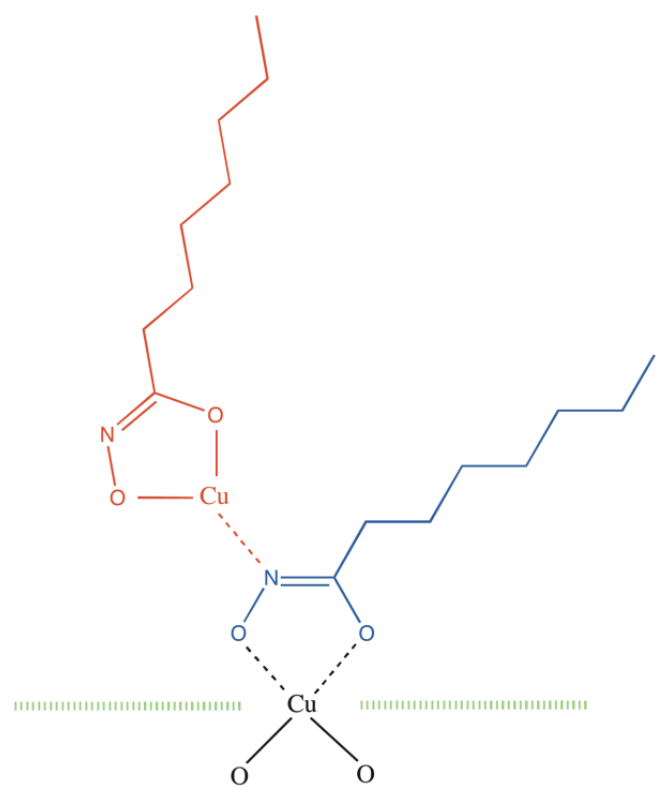


With the Fe oxides, on the other hand, it is believed that each collector anion initially chemisorbs through both its $\mathrm{O}$ atoms to an $\mathrm{Fe}$ atom in the mineral surface as bidentate hydroxamate and with its $\mathrm{N}$ remaining protonated. At greater adsorbate coverage, some collector anions are believed to interact via only one of their $\mathrm{O}$ atoms; in such a chemisorbed monodentate hydroxamate, the $\mathrm{N}$ would be deprotonated but doubly bonded to the adjacent $\mathrm{C}$ atom. No evidence for the formation of multilayer Fe hydroxamate on the Fe oxides under the aqueous conditions described above has been obtained by XPS or Raman spectroscopy for conditioning times of relevance to flotation.

Although the evidence for the different adsorption mechanisms outlined above is robust, the XPS findings have yet to be corroborated. Attempts to obtain surface enhanced Raman scattering (SERS) spectra from these systems via gold decoration of the conditioned oxide mineral surface have not yet been successful, although SERS spectra have been obtained for the oxidised layer on air-exposed pyrite [4]. Conventional Raman spectra have been consistent with the photoelectron spectra, in that multilayer hydroxamate collector adsorbed on oxide $\mathrm{Cu}$ minerals has appeared similar in structure to bulk $\mathrm{Cu}$ hydroximate, and hydroxamate adsorbed on Fe oxides has not been detected for conditioning times of relevance to flotation, an observation in accord with the no more than monolayer coverage expected. Nonetheless, given the importance of the interaction of this collector with $\mathrm{Cu}$ and rare earth oxide minerals on the one hand and $\mathrm{Fe}$ oxides on the other, positive corroboration of the different adsorption mechanisms rather than mere consistency would be desirable. It was for this principal reason that the application of static secondary ion mass spectrometry (SIMS), a surface analytical technique that is much more surface sensitive than conventional vibrational spectroscopy, was investigated to establish whether it could provide the definitive support sought. A secondary reason was to obtain a complementary diagnostic method for the presence of adsorbed $\mathrm{Cu}$ hydroximate or $\mathrm{Fe}$ hydroxamate at the surface of air-exposed $\mathrm{Cu}$-Fe sulfide minerals.

The basis of the anticipation that static SIMS might be able to provide the required information was that the secondary ions detected should predominantly reflect substantial fragments of the chemical species actually present at the conditioned mineral surface prior to impact by the primary ion, rather than fragments of only a "scrambled" impact zone created by the primary ion. It is known that for some materials, stable secondary ions are detected that would not have been present as neutral species at the surface prior to primary ion impact, but it is generally assumed that in static SIMS, a significant proportion of secondary ions detected do reflect the bonding arrangement at the surface [6]. Nevertheless, countering this general assumption has been the limited ability of ToF-SIMS to independently differentiate monolayer and multilayer adsorption of thiol collectors on sulfide minerals [7].

In this investigation, sets of metal-containing diagnostic positive and negative secondary ions were sought for bulk $\mathrm{Cu}$ hydroximate and Fe hydroxamate complexes. If such sets could be established, the diagnostic ions should be the same - and have similar abundances - as those from the corresponding adsorbed multilayer, but not necessarily from the chemisorbed monolayer. Of particular interest was to ascertain whether the $\mathrm{Cu}$ - and Fe-containing diagnostic ions reflected the different bonding arrangements in the two bulk complexes. The secondary ion mass spectra for the bulk complexes were compared with those from surfaces of air-exposed $\mathrm{Cu}$ metal, malachite $\left[\mathrm{Cu}_{2} \mathrm{CO}_{3}(\mathrm{OH})_{2}\right]$, pseudomalachite $\left[\mathrm{Cu}_{5}\left(\mathrm{PO}_{4}\right)_{2}(\mathrm{OH})_{4}\right]$, and magnetite $\left[\mathrm{Fe}_{3} \mathrm{O}_{4}\right]$ conditioned in hydroxamate solution, to establish the presence of adsorbed collector and to determine whether monolayer and multilayer adsorption could be distinguished. Similarly treated surfaces were also characterised by XPS to 
confirm the adsorption of hydroxamate collector under the conditions used, and to establish the likely chemical composition at the solid/vacuum interface.

\section{Results and Discussion}

\subsection{X-ray Photoelectron Spectra of Cu Hydroximate and Fe Hydroxamate}

\subsubsection{Cu Hydroximate XPS}

The X-ray photoelectron spectra of the bulk $\mathrm{Cu}$ hydroximate, $\mathrm{Cu}\left(\mathrm{O}_{2} \mathrm{NCC}_{7} \mathrm{H}_{15}\right)$, characterised in the present investigation were similar to those reported previously for the complex prepared in a two-phase synthesis [8]. In particular, the $\mathrm{N}$ 1s spectrum determined at the start of the spectral suite (Figure 2a) comprised primarily a single component of width $1.4 \mathrm{eV}$ at a binding energy (corrected for overcompensation by the flood-gun electrons) of $400.0 \mathrm{eV}$. A minor component near $402 \mathrm{eV}$ accounting for less than $4 \%$ of the total $\mathrm{N} 1 \mathrm{~s}$ intensity was required for an adequate fit to the spectrum. This small component might have been an artefact of non-uniform charge compensation by the flood-gun electrons. The spectrum determined at the end of the spectral suite was essentially unchanged, indicating that the bulk complex was not susceptible to alteration brought about by the low energy electrons from the flood-gun or by the secondary electrons inherent in the photoemission process. The principal $\mathrm{N}$ 1s component at $400 \mathrm{eV}$ can be assigned to the deprotonated $\mathrm{N}$ of the hydroximate ligand that is interacting with a $\mathrm{Cu}$ atom in a neighbouring $\mathrm{Cu}$ hydroximate molecule in a bonding arrangement similar to that shown in Figure $1[3,8]$. Such a $\mathrm{N}$ chemical environment is also consistent with the Raman spectrum for the complex [8], but the crystal structure of $\mathrm{Cu}$ $n$-octanohydroximate has not been determined because a suitable solvent from which to grow crystals of the complex has yet to be found. Although $\mathrm{Cu}$ hydroximate is definitely a 1:1 $\mathrm{Cu}$ /ligand complex, it is expected that in the solid state, each $\mathrm{Cu}^{\mathrm{II}}$ would be fully coordinated in a multinuclear or oligomeric structure.

\subsubsection{Fe Hydroxamate XPS}

The $\mathrm{N}$ 1s spectrum for the bulk Fe hydroxamate, $\mathrm{Fe}\left(\mathrm{O}_{2} \mathrm{NHCC}_{7} \mathrm{H}_{15}\right)_{3}$, prepared by Hope and co-workers [3] is shown in Figure 2b. This spectrum too primarily comprised a single component of width $1.5 \mathrm{eV}$, but at a corrected binding energy of $401.0 \mathrm{eV}$. Two minor components, each accounting for less than $5 \%$ of the $\mathrm{N} \mathrm{1s}$ intensity, were observed at 399.2 and $407.2 \mathrm{eV}$. The intensity of the component at $399.2 \mathrm{eV}$ increased slightly with analysis time, whereas the $407.2 \mathrm{eV}$ component, which probably arose from a minor impurity, remained unchanged. The minor $399.2 \mathrm{eV}$ component would be consistent with an alteration product brought about by the secondary or flood-gun electrons, but the bulk complex was not significantly susceptible to such beam damage. The principal component at $401.0 \mathrm{eV}$ can be assigned to protonated $\mathrm{N}$ in the hydroxamate ligands [9,10], and this $\mathrm{N}$ chemical environment is consistent with the Raman spectrum for the complex [3] and the crystal structure for the acetohydroxamate analog $\mathrm{Fe}\left(\mathrm{O}_{2} \mathrm{NHCCH}_{3}\right)_{3} \cdot 1.5 \mathrm{H}_{2} \mathrm{O}$ [11]. The other photoelectron spectra from $\mathrm{Fe}$ hydroxamate will be reported elsewhere. 
Figure 2. $\mathrm{N}$ 1s spectrum determined at the start of the spectral suite for: (a) bulk $\mathrm{Cu}$ hydroximate; (b) bulk Fe hydroxamate; (c)-(f) surfaces conditioned in hydroxamate collector: (c) Cu metal; (d) malachite; (e) pseudomalachite; (f) magnetite.

(a)

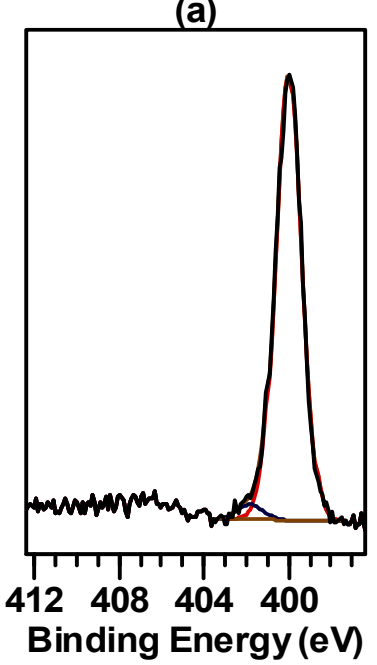

(d)

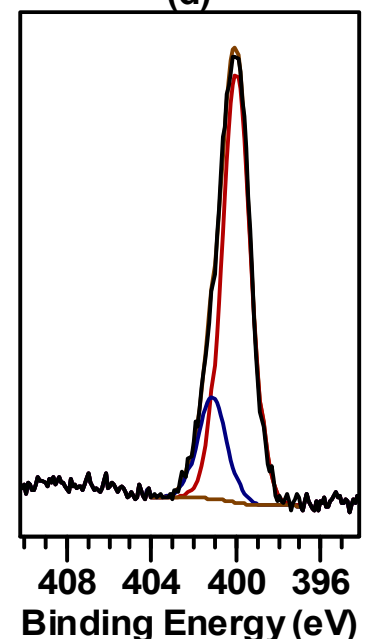

(b)

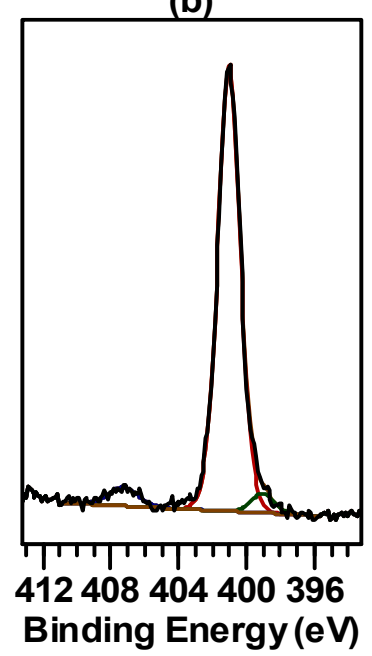

(e)

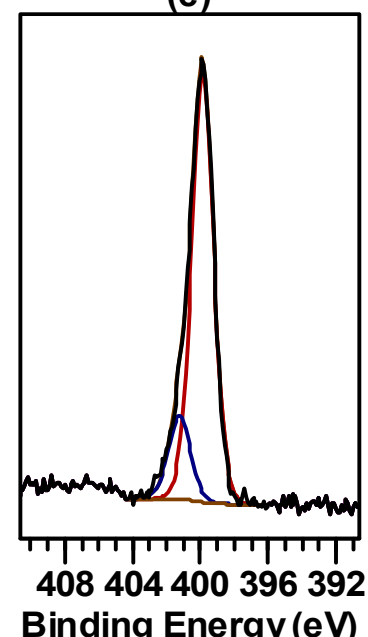

(c)

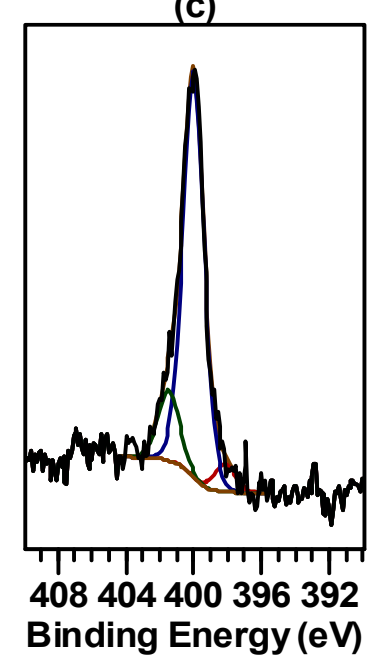

(f)

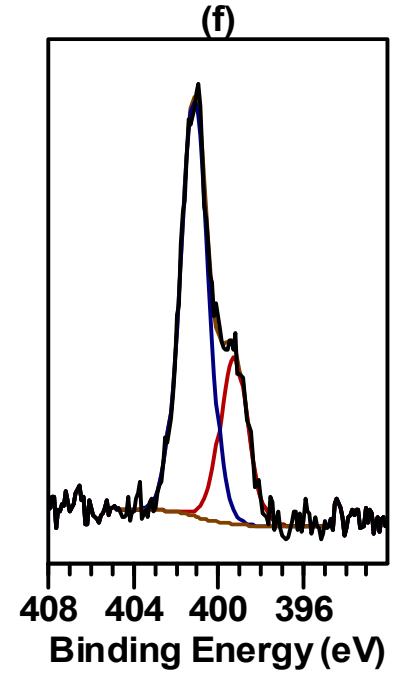

\subsection{Static Secondary Ion Mass Spectra of Cu Hydroximate and Fe Hydroxamate}

\subsection{1. $\mathrm{Cu}$ Hydroximate ToF-SIMS}

Peaks of appreciable intensity (at least $0.5 \%$ of the ${ }^{63} \mathrm{Cu}^{+}$peak intensity) in the secondary ion mass spectra of $\mathrm{Cu}$ hydroximate extended beyond its molecular weight of $220 \mathrm{amu}$. In most cases, $\mathrm{Cu}$-containing ions could be identified with high confidence from the ${ }^{63} \mathrm{Cu}:{ }^{65} \mathrm{Cu}$ stable isotopic ratio of 0.6915:0.3085, whereby ions containing one $\mathrm{Cu}$ gave rise to two peaks with intensity ratio approximately 2.2:1 and separated by $1.998 \mathrm{amu}$, while any ions containing two $\mathrm{Cu}$ atoms would have produced three peaks of intensity ratio $\sim 2: 3: 1$, each separated by $\sim 2$ amu. In this investigation, metal-containing secondary ions were of primary interest as they would be more likely to reflect the different bonding in $\mathrm{Cu}$ hydroximate and $\mathrm{Fe}$ hydroxamate and in the corresponding adsorbed collector systems. The observed $\mathrm{m} / \mathrm{z}$ values for the most abundant $\mathrm{Cu}$-containing secondary ions from $\mathrm{Cu}$ hydroximate are listed in Table 1 with their possible identification, together with selected organic fragment ions. 
The abundances in Table 1 are reported relative to the integrated intensity of the $\mathrm{Cu}^{+}$or $\mathrm{Cu}^{-}$peak, and also to the intensity of the $\mathrm{C}_{5} \mathrm{H}_{11}{ }^{+}$or $\mathrm{C}_{3} \mathrm{H}_{3} \mathrm{O}_{2}{ }^{-}$peak to compare normalisation by metal ions and organic fragments. In Table 1, the peak used for normalisation is evident from the abundance of 1, 10 or 1000 for that ion. In each case the abundances for the eight $200 \mu \mathrm{m} \times 200 \mu \mathrm{m}$ regions of the specimen surface characterised have been tabulated as a range (rather than a weighted mean) to show the variability. The intensity of the $\mathrm{Cu}^{-}$rather than the $\mathrm{CuH}^{-}$peak was used for normalisation, as although the latter was more intense than the former for $\mathrm{Cu}$ hydroximate, the situation was reversed for the spectra from the conditioned $\mathrm{Cu}$ metal and mineral surfaces. The $m / z$ range shown is the variation in measured peak centroid for the eight $200 \mu \mathrm{m} \times 200 \mu \mathrm{m}$ regions. A typical $\mathrm{Cu}$-containing positive secondary ion doublet, tentatively assigned to $\mathrm{CuNCH}_{2}^{+}$rather than $\mathrm{CuC}_{2} \mathrm{H}_{4}^{+}$, is shown in Figure 3 . Broader range secondary ion mass spectra for $\mathrm{Cu}$ hydroximate are shown in Figure 4.

Some other positive $\mathrm{Cu}$-containing ions are also listed in Table 1 because they corresponded to ions that were abundant for Fe hydroxamate (Section 2.2.2) even though they were of low abundance and hence not useful diagnostic ions for $\mathrm{Cu}$ hydroximate. Not listed in Table 1, but of interest when the static SIMS data for conditioned $\mathrm{Cu}$ metal and minerals are being considered, were $\mathrm{CuH}^{+}$peaks with intensity $\sim 1 \%$ of $\mathrm{Cu}^{+}, \mathrm{CuO}^{-}$peaks with intensity $\sim 30 \%$ of $\mathrm{Cu}^{-}$, and $\mathrm{CuO}_{2}^{-}$peaks with intensity $\sim 25 \%$ of $\mathrm{Cu}^{-}$peaks.

Figure 3. Positive secondary ion mass spectrum in the $m / z$ 91-93 region from bulk $\mathrm{Cu}$ hydroximate showing the doublet assigned to ${ }^{63} \mathrm{CuNCH}_{2}{ }^{+}$and ${ }^{65} \mathrm{CuNCH}_{2}^{+}$.

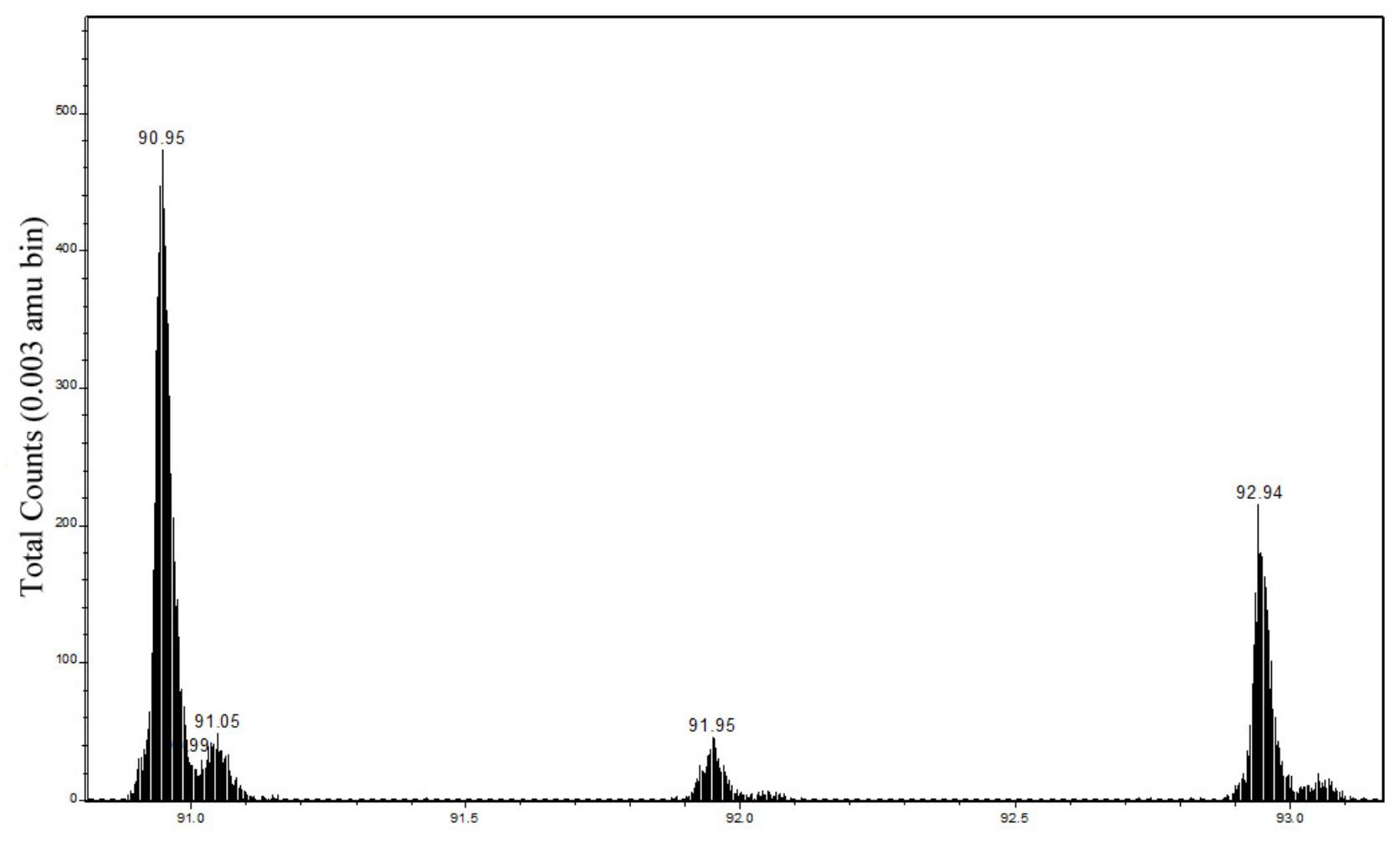


Figure 4. (a) Positive secondary ion mass spectrum in $\mathrm{m} / \mathrm{z} 102-122$ region; and (b) negative secondary ion mass spectrum in $m / z$ 130-150 region from bulk $\mathrm{Cu}$ hydroximate.

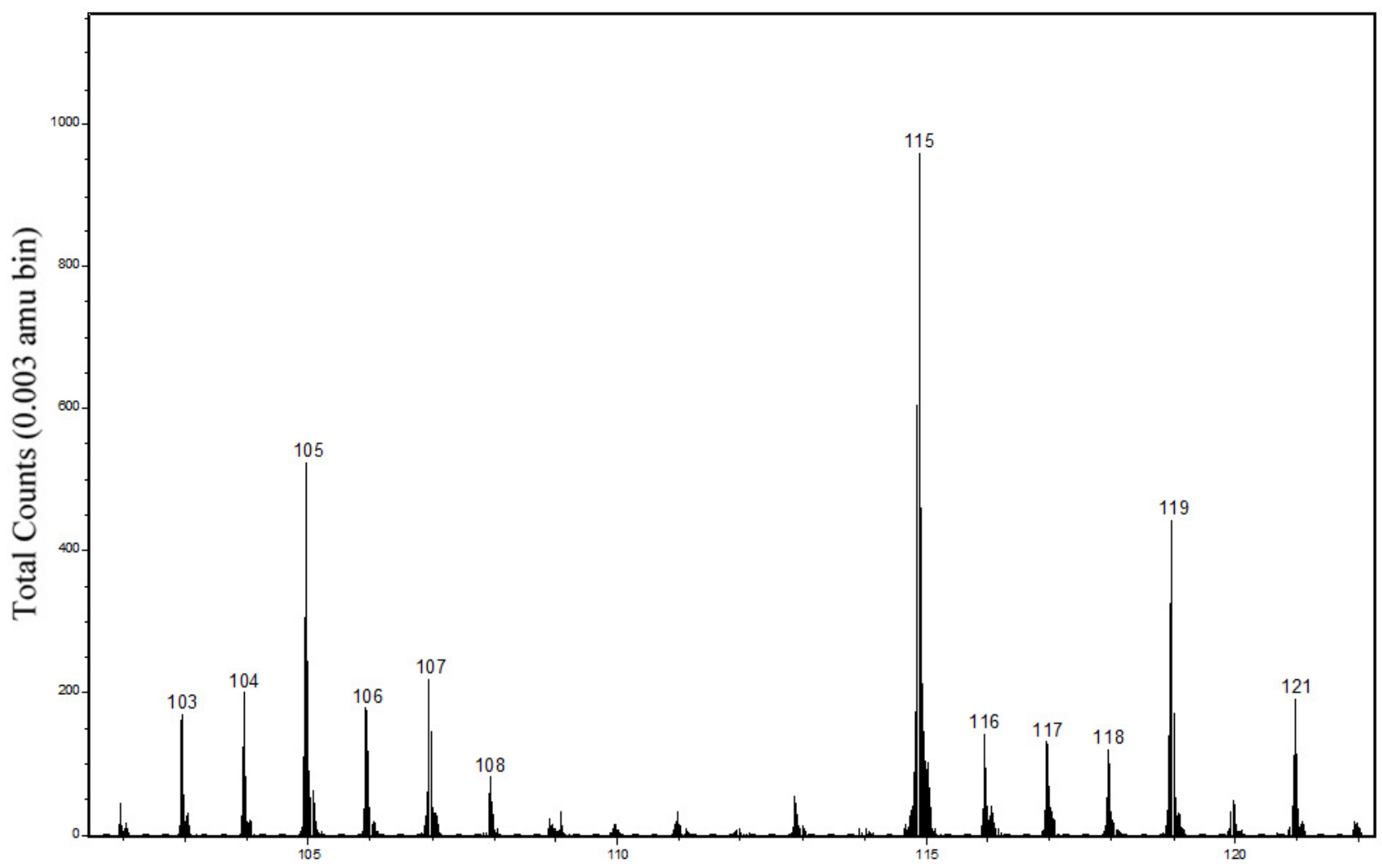

(a)

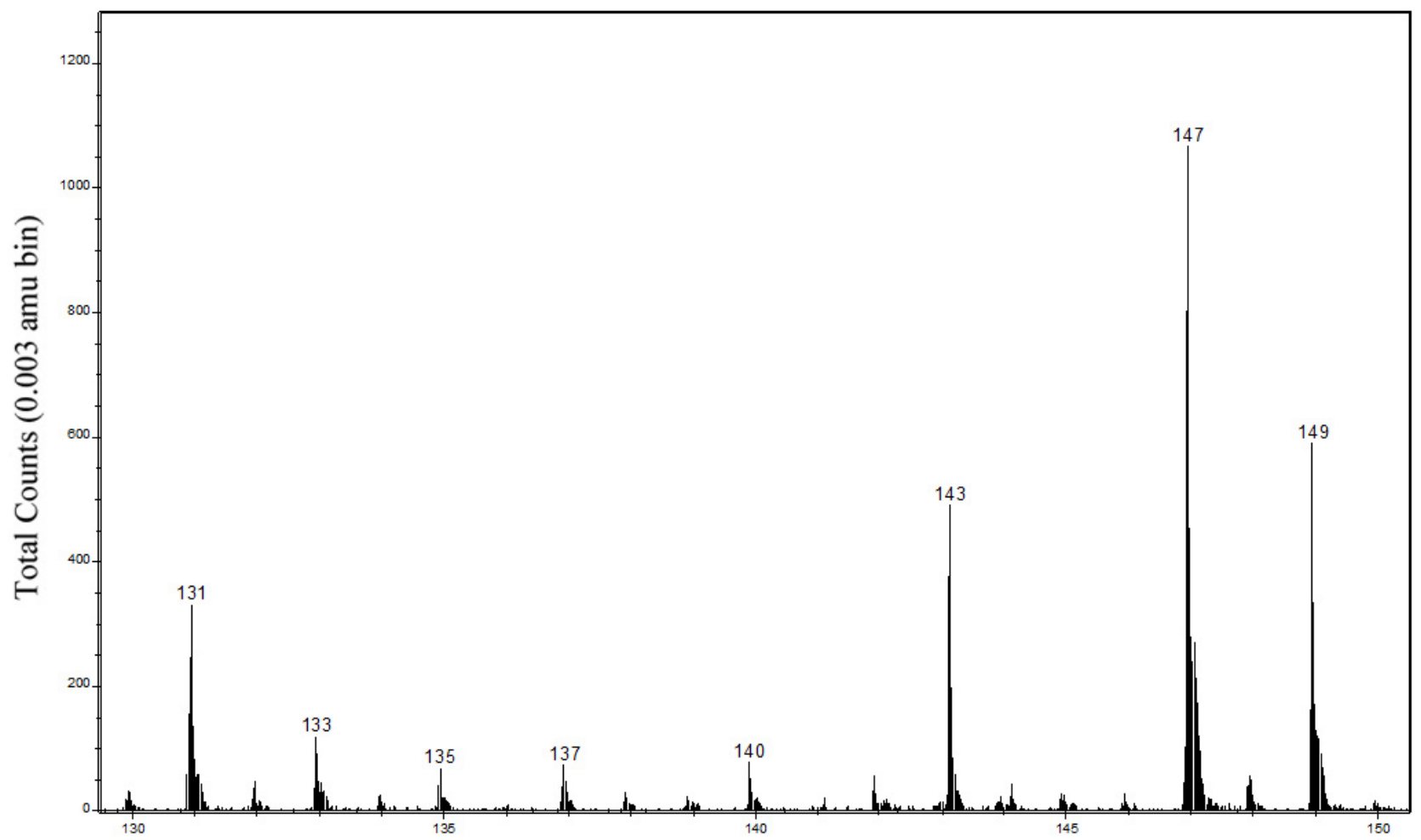

(b) 
Table 1. Diagnostic ions and their observed $\mathrm{m} / \mathrm{z}$ and relative abundance ranges for bulk $\mathrm{Cu}$ hydroximate and conditioned, air-exposed $\mathrm{Cu}$ metal.

\begin{tabular}{|c|c|c|c|c|c|c|c|}
\hline Ion & $\begin{array}{l}\text { Mass } \\
\text { (amu) }\end{array}$ & $\begin{array}{c}\text { Cu hydroximate } \\
\text { observed } m / z \\
\text { range }\end{array}$ & $\begin{array}{c}\text { Cu hydroximate } \\
\text { abundance } \\
\text { (rel. Cu) }\end{array}$ & $\begin{array}{c}\text { Cu hydroximate } \\
\text { abundance } \\
\text { (rel. organic) } \\
\end{array}$ & $\begin{array}{l}\text { Cu metal } \\
\text { observed } \\
m / z \text { range } \\
\end{array}$ & $\begin{array}{c}\text { Cu metal } \\
\text { abundance } \\
\text { (rel. Cu) } \\
\end{array}$ & $\begin{array}{c}\text { Cu metal } \\
\text { abundance } \\
\text { (rel. organic) } \\
\end{array}$ \\
\hline${ }^{39} \mathrm{~K}^{+}$ & 38.9637 & - & - & - & $38.964-38.965$ & $12 \pm 7$ & $3.5 \pm 2$ \\
\hline${ }^{40} \mathrm{Ca}^{+}$ & 39.9626 & - & - & - & $39.961-39.962$ & $33 \pm 6$ & $9 \pm 1.5$ \\
\hline${ }^{63} \mathrm{Cu}^{+}$ & 62.9296 & $62.920-62.932$ & 1,000 & $350 \pm 140$ & $62.924-62.927$ & 1000 & $275 \pm 20$ \\
\hline $\mathrm{C}_{5} \mathrm{H}_{11}{ }^{+}$ & 71.086 & $71.083-71.088$ & $2.9 \pm 0.7$ & 1 & $71.089-71.092$ & $3.6 \pm 0.4$ & 1 \\
\hline $\begin{array}{l}{ }^{63} \mathrm{CuNCH}_{2}{ }^{+} \\
{ }^{63} \mathrm{CuC}_{2} \mathrm{H}_{4}^{+} \\
\end{array}$ & $\begin{array}{l}90.949 \\
90.962 \\
\end{array}$ & $90.951-90.961$ & $47 \pm 4$ & $18 \pm 5$ & $90.954-90.957$ & $36 \pm 2$ & $10 \pm 1$ \\
\hline $\begin{array}{l}{ }^{63} \mathrm{CuNC}_{2} \mathrm{H}_{4}^{+} \\
{ }^{63} \mathrm{CuC}_{3} \mathrm{H}_{6}{ }^{+} \\
\end{array}$ & $\begin{array}{l}104.964 \\
104.977 \\
\end{array}$ & 104.964-104.974 & $10 \pm 1$ & $3.5 \pm 1.5$ & $104.969-104.973$ & $6.1 \pm 0.5$ & $1.9 \pm 0.3$ \\
\hline $\begin{array}{l}{ }^{63} \mathrm{CuNC}_{3} \mathrm{H}_{6}{ }^{+} \\
{ }^{63} \mathrm{CuC}_{4} \mathrm{H}_{8}^{+} \\
\end{array}$ & $\begin{array}{l}118.981 \\
118.994 \\
\end{array}$ & 118.975-118.986 & $8.5 \pm 0.5$ & $3.5 \pm 0.5$ & $118.982-118.987$ & $5.1 \pm 0.2$ & $1.45 \pm 0.1$ \\
\hline $\begin{array}{l}{ }^{63} \mathrm{CuONC}_{2} \mathrm{H}_{3}^{+} \\
{ }^{63} \mathrm{CuOC}_{3} \mathrm{H}_{5}^{+} \\
\end{array}$ & $\begin{array}{l}119.951 \\
119.964 \\
\end{array}$ & $\sim 119.97$ & $<1$ & $<1$ & $\sim 119.98$ & $<1$ & $<1$ \\
\hline $\begin{array}{l}{ }^{63} \mathrm{CuO}_{2} \mathrm{NCH}_{2}^{+} \\
{ }^{63} \mathrm{CuO}_{2} \mathrm{C}_{2} \mathrm{H}_{4}^{+}\end{array}$ & $\begin{array}{l}122.939 \\
122.951 \\
\end{array}$ & $\sim 122.96$ & $<1$ & $<1$ & $\sim 122.95$ & $<1$ & $<1$ \\
\hline $\begin{array}{l}\text { (hydroxamic } \\
\text { acid) }\end{array}$ & 159.126 & $159.012-159.021$ & $0.38 \pm 0.03$ & $0.16 \pm 0.02$ & $159.140-159.151$ & $5 \pm 4$ & $1.1 \pm 1$ \\
\hline${ }^{63} \mathrm{Cu}^{-}$ & 62.9296 & $62.928-62.933$ & 10 & $7.5 \pm 4$ & $62.930-62.932$ & 10 & $1.8 \pm 0.2$ \\
\hline${ }^{63} \mathrm{CuH}^{-}$ & 63.9374 & $63.944-63.947$ & $15 \pm 0.5$ & $12 \pm 5$ & $63.937-63.951$ & $3 \pm 1.5$ & $3 \pm 1.3$ \\
\hline $\mathrm{C}_{3} \mathrm{H}_{3} \mathrm{O}_{2}^{-}$ & 71.0133 & $71.017-71.022$ & $2 \pm 1$ & 1 & 71.017-71.018 & $5 \pm 1$ & 1 \\
\hline $\mathrm{C}_{4} \mathrm{H}_{9} \mathrm{O}^{-}$ & 73.065 & $73.067-73.072$ & $0.7 \pm 0.2$ & $0.7 \pm 0.4$ & $73.054-73.072$ & $0.4 \pm 0.05$ & $0.07 \pm 0.02$ \\
\hline $\begin{array}{l}{ }^{63} \mathrm{CuONCH}^{-} \\
{ }^{63} \mathrm{CuOC}_{2} \mathrm{H}_{3}^{-} \\
\end{array}$ & $\begin{array}{l}105.935 \\
105.948 \\
\end{array}$ & 105.939-105.944 & $6 \pm 1$ & $4.4 \pm 2$ & $105.940-105.943$ & $6.8 \pm 0.5$ & $1.2 \pm 0.2$ \\
\hline $\begin{array}{l}{ }^{63} \mathrm{CuO}_{2} \mathrm{NCH}^{-} \\
{ }^{63} \mathrm{CuO}_{2} \mathrm{C}_{2} \mathrm{H}_{3}{ }^{-}\end{array}$ & $\begin{array}{l}121.930 \\
121.943 \\
\end{array}$ & 121.934-121.939 & $10 \pm 2$ & $8.7 \pm 3$ & $121.937-121.938$ & $14.5 \pm 1$ & $2.4 \pm 0.2$ \\
\hline $\begin{array}{l}{ }^{63} \mathrm{CuONC}_{3} \mathrm{H}_{2}^{-} \\
{ }^{63} \mathrm{CuOC}_{4} \mathrm{H}_{4}^{-} \\
\end{array}$ & $\begin{array}{r}130.943 \\
130.956 \\
\end{array}$ & $130.936-130.942$ & $7 \pm 0.8$ & $6 \pm 1.5$ & $130.937-130.940$ & $7.5 \pm 0.5$ & $1.2 \pm 0.1$ \\
\hline $\begin{array}{l}{ }^{63} \mathrm{CuO}_{2} \mathrm{NC}_{3} \mathrm{H}_{2}^{-} \\
{ }^{63} \mathrm{CuO}_{2} \mathrm{C}_{4} \mathrm{H}_{4}^{-}\end{array}$ & $\begin{array}{c}146.938 \\
146.951 \\
\end{array}$ & 146.933-146.939 & $26 \pm 5$ & $24 \pm 6$ & $146.934-146.937$ & $32 \pm 2$ & $5.5 \pm 0.6$ \\
\hline $\begin{array}{l}\text { (hydroxamic } \\
\text { acid-H) }\end{array}$ & 158.118 & $158.111-158.123$ & $0.21 \pm 0.01$ & $0.20 \pm 0.01$ & $158.119-158.129$ & $0.6 \pm 0.1$ & $0.10 \pm 0.02$ \\
\hline
\end{tabular}

It is pertinent to note that the most abundant positive $\mathrm{Cu}$-containing ions did not also contain $\mathrm{O}$, whereas the most abundant negative $\mathrm{Cu}$-containing ions all contained at least one $\mathrm{O}$ atom. The $\mathrm{Cu}$ analogs of the largest, abundant, Fe-containing positive ions observed for $\mathrm{Fe}$ hydroxamate (Section 2.2.2), viz, $\mathrm{CuONC}_{2} \mathrm{H}_{3}^{+}(119.951 \mathrm{amu})$ or $\mathrm{CuOC}_{3} \mathrm{H}_{5}{ }^{+}\left(119.964 \mathrm{amu}\right.$ for $\left.{ }^{63} \mathrm{Cu}\right)$ and $\mathrm{CuO}_{2} \mathrm{NCH}_{2}{ }^{+}$(122.939 amu) or $\mathrm{CuO}_{2} \mathrm{C}_{2} \mathrm{H}_{4}{ }^{+}$(122.951 amu for ${ }^{63} \mathrm{Cu}$ ), were of very low abundance for $\mathrm{Cu}$ hydroximate.

It can be seen from Table 1 that distinguishing ions containing $\mathrm{N}$ (14.003 amu) from those containing $\mathrm{CH}_{2}$ (14.016 amu) was not as straightforward as might have been expected given the spectral resolution of $\sim 8000$. The two main reasons for this uncertainty were the determination of $\mathrm{m} / \mathrm{z}$ 
values outside the range that could be calibrated reliably, and the specimen surface roughness at the microscopic level (Section 3.3). Nevertheless, for the negative $\mathrm{Cu}$-containing secondary ions in particular, assignment of the observed diagnostic peak to the $\mathrm{N}$ rather than $\mathrm{CH}_{2}$ species appeared to be justified. However, even if correct, that assignment would not have constituted support for the hydroximate structure and $\mathrm{Cu}-\mathrm{N}$ interaction, as it will be seen below (Section 2.2.2) that the analogous Fe-containing negative ions from Fe hydroxamate also appeared to be the $\mathrm{N}$ rather than $\mathrm{CH}_{2}$ species. Therefore, it would appear that these secondary ions do not necessarily reflect the structure prior to impact by the primary ions.

Among the ions not containing $\mathrm{Cu}$, there were no abundant ones near $\mathrm{m} / \mathrm{z} 220$ or 221 that might have been the parent $\mathrm{Cu}$ hydroximate ion or its protonated analog. No abundant secondary ions containing two $\mathrm{Cu}$ atoms were positively identified, although peaks at $\mathrm{m} / z$ 247.765, 249.763 and 251.764 were observed in the positive ion spectra with approximately the correct intensity ratio. One possible origin might have been $\left(\mathrm{Cu}-\mathrm{O}-\mathrm{N}-\mathrm{Cu}-\mathrm{O}_{2} \mathrm{C}_{5}\right)$ ions, with the ${ }^{63} \mathrm{Cu}^{+}{ }^{63} \mathrm{Cu}$ peak of mass $247.848 \mathrm{amu}$, but because those peaks were so far outside the calibration range, their assignment remains uncertain. Neither a positive ion peak near $m / z$ 159.126, that for a surface conditioned in hydroxamate collector might have been assigned to adsorbed $n$-octanohydroxamic acid, nor a negative ion peak near $m / z$ 158.118, that might have been assigned to (acid $-\mathrm{H}$ ) ${ }^{-}$ions, was of appreciable abundance. Although abundances greater than zero have been shown for those ions in Table 1, the corresponding peak intensities were barely greater than noise level.

\subsubsection{Fe Hydroxamate ToF-SIMS}

Peaks of appreciable intensity in the secondary ion mass spectra from Fe hydroxamate extended to near its molecular weight of about $530 \mathrm{amu}$. The identification of Fe-containing ions was less definite than for $\mathrm{Cu}$-containing ions, as ${ }^{56} \mathrm{Fe}$ with mass $55.935 \mathrm{amu}$ accounts for $91.75 \%$ of the stable isotopic composition of $\mathrm{Fe}$, so that each Fe-containing ion gives rise to only a single substantial peak. The most abundant of the Fe-containing secondary ions, selected impurity element ions and organic fragment ions are listed in Table 2. Also listed in Table 2 are the relative abundances of negative ions of $m / z \sim 139.95$, that could be assigned to ${ }^{56} \mathrm{FeO}_{2} \mathrm{NC}_{3} \mathrm{H}_{2}{ }^{-}$or ${ }^{56} \mathrm{FeO}_{2} \mathrm{C}_{4} \mathrm{H}_{4}{ }^{-}$, not because they were useful diagnostic ions for $\mathrm{Fe}$ hydroxamate but because they corresponded to the strong ${ }^{63} \mathrm{Cu}$-containing diagnostic peak near $\mathrm{m} / \mathrm{z} 146.9$ for $\mathrm{Cu}$ hydroximate. Abundances were normalised by the integrated intensities of peaks from $\mathrm{Fe}^{+}$or $\mathrm{FeH}^{-}$and $\mathrm{C}_{4} \mathrm{H}_{9}{ }^{+}$or $\mathrm{O}_{2} \mathrm{C}_{2} \mathrm{H}_{2}{ }^{-}$ions, and the observed $\mathrm{m} / \mathrm{z}$ ranges across the eight $200 \mu \mathrm{m} \times 200 \mu \mathrm{m}$ regions characterised are tabulated. In Table 2 , the peak used for normal- isation is evident from the abundance of 10,100 or 1000 for that ion.

The largest of the most abundant Fe-containing positive secondary ions for Fe hydroxamate also contained one or two $\mathrm{O}$ atoms, unlike the positive diagnostic secondary ions for $\mathrm{Cu}$ hydroximate. As noted in Section 2.2.1, the $\mathrm{Cu}$ analogs of the largest, abundant, Fe-containing positive ions observed for Fe hydroxamate, viz, $\mathrm{CuONC}_{2} \mathrm{H}_{3}{ }^{+}(119.951 \mathrm{amu})$ or $\mathrm{CuOC}_{3} \mathrm{H}_{5}{ }^{+}\left(119.964 \mathrm{amu}\right.$ for $\left.{ }^{63} \mathrm{Cu}\right)$ and $\mathrm{CuO}_{2} \mathrm{NCH}_{2}{ }^{+}$(122.939 amu) or $\mathrm{CuO}_{2} \mathrm{C}_{2} \mathrm{H}_{4}{ }^{+}$(122.951 amu for ${ }^{63} \mathrm{Cu}$ ), were of very low abundance for $\mathrm{Cu}$ hydroximate. The metal-containing ions concerned would be consistent with the proposed structures for both $\mathrm{Cu}$ hydroximate and $\mathrm{Fe}$ hydroxamate, and the $m / z$ values for the $\mathrm{Cu}$-containing ions are only marginally higher than for the positive ions that were observed with appreciable abundance. 
Table 2. Diagnostic ions and their observed $\mathrm{m} / \mathrm{z}$ and relative abundance ranges for bulk $\mathrm{Fe}$ hydroxamate and conditioned magnetite $\left(\mathrm{Fe}_{3} \mathrm{O}_{4}\right)$.

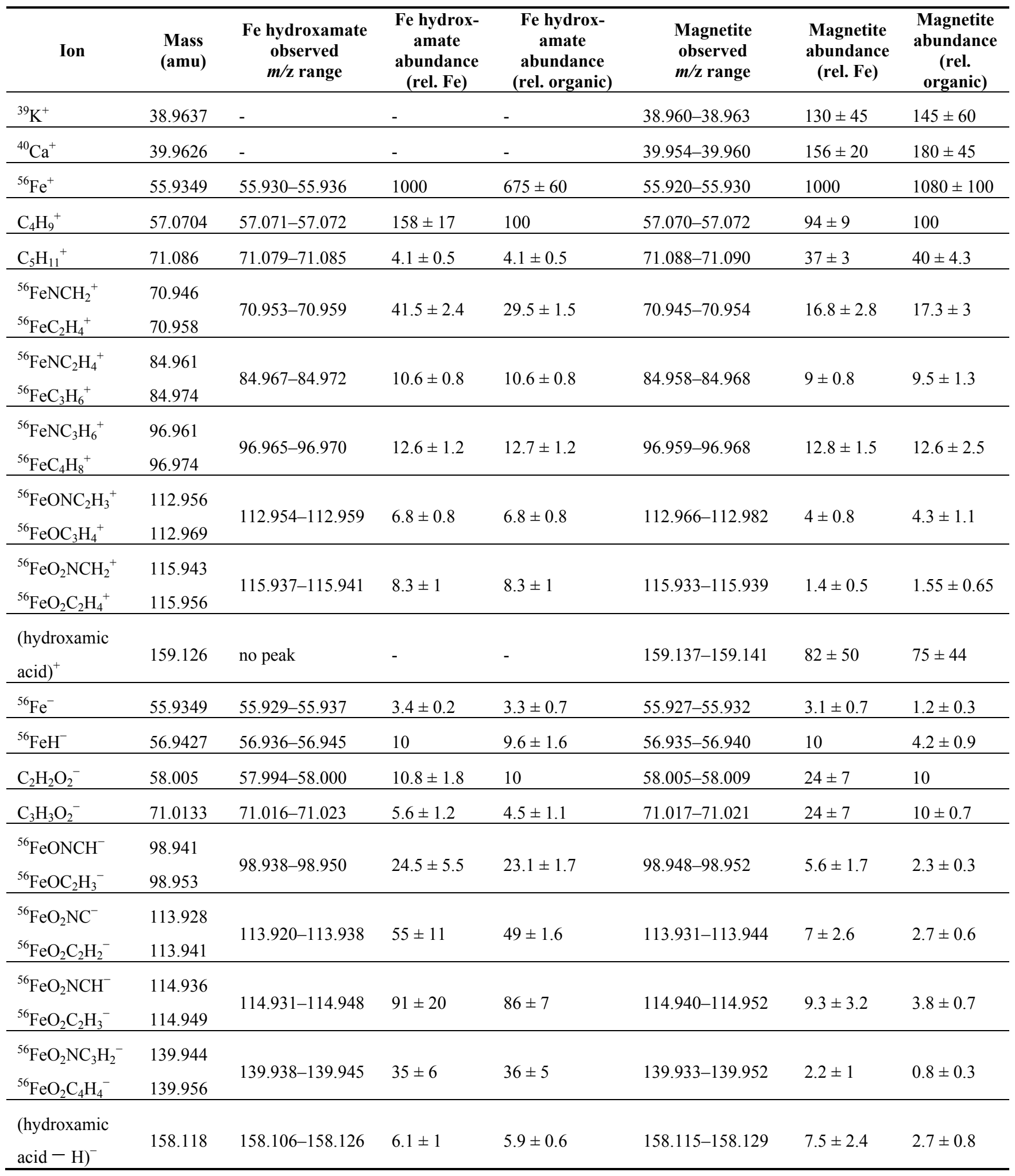

The difference can be partly rationalised by each Fe atom in Fe hydroxamate being coordinated by the six $\mathrm{O}$ atoms of three hydroxamate ligands, so that any moderately large Fe-containing secondary ion would be expected to contain at least one $\mathrm{O}$. On the other hand, while each $\mathrm{Cu}$ atom in $\mathrm{Cu}$ hydroximate would be coordinated by the two $\mathrm{O}$ atoms of one ligand, it is believed to interact with the 
$\mathrm{N}$ atom of an adjacent ligand, and it might also have other ligand atoms as neighbours in its presumed oligomeric form in the solid state. Therefore not all large $\mathrm{Cu}$-containing secondary ions would necessarily be expected to also contain $\mathrm{O}$.

Apart from the difference in metal-containing positive ions discussed above, it can be seen from Tables 1 and 2 that there is no obvious difference in the organic structure of the other diagnostic ions for the two bulk complexes. In particular, the smaller, abundant Fe-containing positive ions also contained either $\mathrm{N}$ or $\mathrm{CH}_{2}$, but not $\mathrm{O}$. In other words, the most abundant fragment secondary ions did not clearly distinguish between the different bonding arrangements in the $\mathrm{Cu}$ and $\mathrm{Fe}$ complexes expected from spectroscopic and solubility data, and therefore do not corroborate the structures deduced from XPS and Raman spectroscopy. Because of those different structures of the two complexes, it might have been expected that secondary ions containing $\mathrm{Cu}$ and $\mathrm{N}$ but no $\mathrm{O}$ would have been observed, whereas ions containing $\mathrm{Fe}$ and $\mathrm{N}$ without $\mathrm{O}$ should not have been abundant unless rearrangement prior to ion ejection had occurred. In $\mathrm{Cu}$ hydroximate, there is intermolecular interaction between $\mathrm{Cu}$ and $\mathrm{N}$ atoms, whereas in Fe hydroxamate, the $\mathrm{N}$ atoms are protonated and the $\mathrm{Fe}$ atoms are fully coordinated by the six $\mathrm{O}$ atoms of three hydroxamate ligands. Given the unambiguous nature of the XPS and Raman spectroscopic information, it is highly likely that such rearrangement was common adjacent to the $\mathrm{Au}^{+}$primary ion impact zone. It is just possible that the negative ion peak near $\mathrm{m} / \mathrm{z} 146.94 \mathrm{amu}$ for $\mathrm{Cu}$ hydroximate arose from ${ }^{63} \mathrm{CuO}_{2} \mathrm{NC}_{3} \mathrm{H}_{2}{ }^{-}$rather than ${ }^{63} \mathrm{CuO}_{2} \mathrm{C}_{4} \mathrm{H}_{4}^{-}$, while that near 139.94 amu for $\mathrm{Fe}$ hydroxamate arose from ${ }^{56} \mathrm{FeO}_{2} \mathrm{C}_{4} \mathrm{H}_{4}{ }^{-}$rather than ${ }^{56} \mathrm{FeO}_{2} \mathrm{NC}_{3} \mathrm{H}_{2}{ }^{-}$, for example, but it is considered improbable.

Also because of the difference in the structures of the $\mathrm{Cu}$ and Fe complexes, especially the three hydroxamate ligands coordinating the $\mathrm{Fe}$ in the latter, it might be expected that ions containing $\mathrm{CuO}_{x} \mathrm{NC}_{y} \mathrm{H}_{z}$ would not be observed for $x>4$ but that those containing $\mathrm{FeO}_{x} \mathrm{NC}_{y} \mathrm{H}_{z}$ might be observed for $x>4$. This expectation was largely met, in that there were relatively intense peaks attributable to ions such as ${ }^{56} \mathrm{FeO}_{5} \mathrm{NC}_{3} \mathrm{H}^{-},{ }^{56} \mathrm{FeO}_{6} \mathrm{NC}^{-}$and ${ }^{56} \mathrm{FeO}_{6} \mathrm{NC}_{3} \mathrm{H}^{-}$, but no peaks that could have been assigned to the corresponding $\mathrm{Cu}$ ions such as ${ }^{63} \mathrm{CuO}_{5} \mathrm{NC}_{3} \mathrm{H}^{-}$at $m / z 193.916$ or ${ }^{63} \mathrm{CuO}_{6} \mathrm{NC}_{3} \mathrm{H}^{-}$at $m / z$ 209.911. Although the $\mathrm{Cu}$ in a $\mathrm{Cu}$ hydroximate molecule is bonded to the two $\mathrm{O}$ atoms in a single hydroximate ligand, in the 3-dimensional and probably oligomeric structure of the bulk complex, each $\mathrm{Cu}$ atom might interact with up to four $\mathrm{O}$ atoms and two $\mathrm{N}$ atoms. Thus the observed secondary ions were consistent with the number of $\mathrm{O}$ nearest neighbours of the metal atoms in the two bulk complexes.

Notwithstanding the fact that the relatively abundant ions listed in Tables 1 and 2 do not appear to reflect the different $\mathrm{N}$ bonding in the $\mathrm{Cu}$ and $\mathrm{Fe}$ complexes, they should nevertheless be diagnostic secondary ions for multilayer $\mathrm{Cu}$ hydroximate or $\mathrm{Fe}$ hydroxamate adsorbed on oxide $\mathrm{Cu}$ or $\mathrm{Fe}$ minerals. The same ions might also be diagnostic for hydroxamate collector chemisorbed to $\mathrm{Cu}$ or $\mathrm{Fe}$ atoms in a mineral surface, but that can only be established by characterising surfaces bearing such an adsorbate. 


\subsection{X-ray Photoelectron Spectra of Conditioned Cu and Fe Oxide Surfaces}

\subsubsection{Conditioned $\mathrm{Cu}$ Metal and $\mathrm{Cu}$ Mineral XPS}

XPS data for surfaces of $\mathrm{Cu}$ metal, malachite and pseudomalachite that had been abraded in air prior to conditioning in nominally saturated aqueous solutions of potassium hydrogen $n$-octanohydroxamate have been reported previously [12]. It had been found that collector coverage on $\mathrm{Cu}$ metal depended on the extent of oxidation and conditioning times, but conditioning of the minerals in the collector solution for only short periods had resulted in the adsorption of multilayer $\mathrm{Cu}$ hydroximate. The $\mathrm{Cu} 2 \mathrm{p}$ spectra indicated that the multilayer $\mathrm{Cu}$ hydroximate had been only a few monolayers thick, and the $\mathrm{N} 1 \mathrm{~s}$ spectra had suggested the presence of some co-adsorbed hydroxamic acid, as in addition to the principal $\mathrm{N} 1 \mathrm{~s}$ component at $400.0 \mathrm{eV}$, about $15 \%$ of the $\mathrm{N} 1 \mathrm{~s}$ intensity had been near $401.2 \mathrm{eV}$ [12]. To confirm a similar type and extent of coverage on the specimens characterised by ToF-SIMS (Section 2.4), X-ray photoelectron spectra were determined for the same conditioning time ( $2 \mathrm{~min}$ ) of $\mathrm{Cu}$ metal and mineral surfaces prepared in the same way.

The $\mathrm{N}$ 1s spectra for air-exposed $\mathrm{Cu}$ metal, malachite and pseudomalachite surfaces conditioned for $2 \mathrm{~min}$ in hydroxamate collector solution are shown in Figure 2c-e. As observed previously, in each case the principal component was at a binding energy of $400.0 \mathrm{eV}$, consistent with hydroxamate collector chemisorbed to $\mathrm{Cu}$ atoms in the oxide surface layer and, for the minerals, a thin layer of molecular $\mathrm{Cu}$ hydroximate covering the chemisorbed monolayer. In both monolayer and multilayer $\mathrm{Cu}$ hydroximate, each $\mathrm{N}$ atom would be deprotonated but interacting with a $\mathrm{Cu}$ atom. Also as observed previously, there was a minor unresolved component between 401.2 and $401.5 \mathrm{eV}$ that would have arisen from protonated $\mathrm{N}$. That protonated $\mathrm{N}$ would most probably have been in co-adsorbed hydroxamic acid. Such co-adsorption of acid would not be surprising as the $\mathrm{pH}$ of the potassium hydrogen $n$-octanohydroxamate solution would have been close to the $p K_{\mathrm{a}}$ for $n$-octanohydroxamic acid, and indeed, co-adsorption of the acid had been proposed some years ago by Fuerstenau and Pradip [13]. For the air-exposed $\mathrm{Cu}$ metal surface, the $\mathrm{N}$ concentration (3.3 atom \%) was about half that for the minerals, suggesting that the collector coverage of the former was predominantly monolayer only. In the $\mathrm{N}$ 1s spectrum obtained with the flood-gun off (Figure 2c), a component near $401.5 \mathrm{eV}$ accounting for $\sim 15 \%$ of the intensity was required for an adequate fit. However, under the influence of a beam of $\sim 4.5 \mathrm{eV}$ electrons from the flood-gun, but with the specimen still earthed, the principal component near $400 \mathrm{eV}$ remained unshifted but the $\mathrm{N} 1$ s component previously observed at higher binding energy was shifted by about $4.5 \mathrm{eV}$ to $\sim 396.5 \mathrm{eV}$. This behaviour established that the species containing protonated hydroxamate $\mathrm{N}$ was in poor electrical contact with the air-exposed $\mathrm{Cu}$ substrate, and its $\mathrm{N}$ 1s component would probably have been charge-shifted by up to $0.5 \mathrm{eV}$ above $401 \mathrm{eV}$ in the absence of the low energy electron beam. Hence that species was much more likely to have been co-adsorbed hydroxamic acid than multilayer $\mathrm{Cu}$ hydroximate. The $\mathrm{Cu} 2 \mathrm{p}, \mathrm{C}$ 1s and $\mathrm{O}$ 1s spectra determined with the flood-gun off and on were consistent with this conclusion. The low intensity component at $398.2 \mathrm{eV}$ can be assigned to $\mathrm{N}$ in an hydroxamate decomposition product.

It is important to note that no $\mathrm{K}$ was observed at the conditioned $\mathrm{Cu}$ metal or oxide mineral surfaces. Any residual $\mathrm{K}$ from potassium hydrogen hydroxamate that had not been rinsed from the surface with water following the conditioning period would have been evident from a $\mathrm{K} 2 \mathrm{p}$ doublet 
near 293 and $296 \mathrm{eV}$. For the Cu metal, a Ca 2p doublet near 347 and $350.5 \mathrm{eV}$ was not discernible, indicating that any $\mathrm{Ca}$ impurity would have had a surface concentration below 0.1 atom \%. For the conditioned malachite, a low intensity $\mathrm{Ca} 2 \mathrm{p}$ doublet indicated a surface concentration of 0.4 atom $\%$ $\mathrm{Ca}$ and a barely detectable $\mathrm{Mg} 1 \mathrm{~s}$ peak indicated a $\mathrm{Mg}$ concentration of no more than $0.1 \mathrm{atom} \%$. For the conditioned pseudomalachite, a very low surface concentration $(<0.1$ atom $\%)$ of $\mathrm{Ca}$ was just discernible, but no other impurity elements were observed.

\subsubsection{Conditioned Magnetite XPS}

X-ray photoelectron spectra for a surface of magnetite abraded in air immediately prior to conditioning in hydroxamate solution for $5 \mathrm{~min}$ indicated the adsorption of no more than a monolayer of chemisorbed hydroxamate. A shorter conditioning time had been used for the $\mathrm{Cu}$ systems because of multilayer formation within $2 \mathrm{~min}$ in those systems. None of the spectra determined with or without a low energy electron beam from a flood-gun provided evidence for the presence of co-adsorbed hydroxamic acid. The Fe $2 p$ spectrum revealed that some $\mathrm{Fe}^{\mathrm{II}}$ remained within the depth analysed, but the spectrum was consistent with the $\mathrm{Fe}^{\mathrm{II}}$ in the outermost layers having been oxidised to $\mathrm{Fe}^{\mathrm{III}}$. The $\mathrm{N}$ 1s spectrum determined at the start of the spectral suite (without the use of a flood-gun) is shown in Figure 2f. The signal-to-noise of that spectrum is low both because of the low $\mathrm{N}$ surface concentration $(2.5$ atom \%) and because the spectrum was determined as quickly as possible in order to monitor any beam-induced changes. The spectrum in Figure $2 \mathrm{f}$ could be fitted with two components of width $1.55 \mathrm{eV}$, the main one accounting for $70 \%$ of the $\mathrm{N} 1 \mathrm{~s}$ intensity at $401.0 \mathrm{eV}$ and a lower binding energy component at $399.2 \mathrm{eV}$. The component at $401.0 \mathrm{eV}$ can be assigned to protonated $\mathrm{N}$ in bidentate hydroxamate chemisorbed through both its $\mathrm{O}$ atoms to an Fe atom in the oxide surface. A second $\mathrm{N} 1 \mathrm{~s}$ spectrum determined at the end of the spectral suite could be fitted with components at the same binding energies, but the $401.0 \mathrm{eV}$ component now accounted for only $64 \%$ of the intensity. The origin and increase in intensity of the $399.2 \mathrm{eV}$ component will be explored in detail elsewhere, but it is tentatively proposed that the lower binding energy component arises from deprotonated $\mathrm{N}$ in chemisorbed monodentate hydroxamate. There is strong evidence to suggest that some of this monodentate species is present before any irradiation by the X-ray beam, but that its surface concentration increases moderately as a result of secondary electron alteration. Of most relevance to the present investigation is confirmation of no more than monolayer coverage of the hydroxamate collector arising from the $5 \mathrm{~min}$ conditioning period. In fact no more than monolayer coverage on magnetite has been observed for conditioning periods of up to $30 \mathrm{~min}$ under similar conditions. No residual $\mathrm{K}$ was detected at the conditioned and rinsed magnetite surfaces.

\subsection{Static Secondary Ion Mass Spectra of Conditioned Cu and Fe Oxide Surfaces}

In static SIMS, the sputtering of material from a surface results from a "collision cascade" initiated by the impact of the primary ion. For organic adsorbates, it is generally assumed that in the central impact region, mostly atomic and non-characteristic small organic fragments are generated, but immediately outside this impact region, more extensive fragments that may have undergone some structural rearrangement are produced. Further away from the impact region, the energy available for rearrangement is lower, so that larger and minimally rearranged fragment ions (and even parent ions) 
might be expected. On this basis, it might be anticipated that the larger diagnostic secondary ions should better reflect species present at the surface prior to the primary ion impact. However, as discussed in Section 3.3, the larger the secondary ion, the greater the need to extrapolate the mass range calibration; i.e., the more relevant the diagnostic ion, the more uncertain its measured $\mathrm{m} / \mathrm{z}$ value.

\subsubsection{Conditioned $\mathrm{Cu}$ Metal ToF-SIMS}

For $\mathrm{Cu}$ metal surfaces that had been freshly abraded in air, then conditioned for $2 \mathrm{~min}$ in hydroxamate collector solution and subsequently rinsed with water, peaks of moderate intensity were observed in the positive secondary ion spectrum at $\mathrm{m} / \mathrm{z} 38.964$ and 39.961. The former could be assigned to $\mathrm{K}^{+}$and the latter to $\mathrm{Ca}^{+}$rather than $\mathrm{KH}^{+}$(Table 1). In making that assignment, it should be noted that ${ }^{39} \mathrm{~K}$ with atomic mass 38.9637 accounts for more than $93.2 \%$ of the $\mathrm{K}$ stable isotopes, and ${ }^{40} \mathrm{Ca}$ with atomic mass 39.9626 accounts for $96.9 \%$ of the Ca stable isotopes. Mostly because of its low $(\sim 4.3 \mathrm{eV})$ ionisation potential, $\mathrm{K}$ has one of the highest secondary ion yields, so that a very low surface concentration would be expected to give rise to a discernible peak at $m / z$ 38.964. Ca has a somewhat higher $(\sim 6.1 \mathrm{eV})$ ionisation potential and hence lower secondary ion yield. Indeed, measured secondary ion yields from $\mathrm{Au}^{+}$primary ions reported by King et al. [14] for selected elements in glass standards included 1400 for K, 154 for $\mathrm{Ca}$ and 45 for Fe. XPS analysis of $\mathrm{Cu}$ metal surfaces conditioned similarly to those characterised by ToF-SIMS showed that neither the Ca nor residual $\mathrm{K}$ surface concentration should have been significant $(>0.1$ atom \%). Any Ca present below the XPS detection limit might have been an impurity introduced by the surface abrasion immediately before the specimen was conditioned in the collector solution or an impurity in the potassium hydrogen $n$-octanohydroxamate itself.

Also in each positive secondary ion spectrum was a low intensity peak at $m / z$ 159.151 (Table 1). This $\mathrm{m} / \mathrm{z}$ value is well outside the calibration range, so it might have arisen from parent hydroxamic acid ions of mass $159.126 \mathrm{amu}$. There was an even weaker peak at $m / z 160.151$ that might be assigned to $(\text { acid }+\mathrm{H})^{+}$ions of mass $160.137 \mathrm{amu}$. In each corresponding negative secondary ion spectrum, there was no peak near $\mathrm{m} / \mathrm{z} 159.1$ and only very weak peaks at $\mathrm{m} / \mathrm{z} 158.125$ and 157.118 that might have arisen from $(\mathrm{acid}-\mathrm{H})^{-}$and $(\mathrm{acid}-2 \mathrm{H})^{-}$ions with mass 158.118 and $157.110 \mathrm{amu}$, respectively. Assuming those assignments were correct, it cannot be concluded that a low concentration of hydroxamic acid was necessarily present at the surface, as it is conceivable that chemisorbed hydroximate (157.110 amu) might have captured one or two protons prior to abstraction from the impact zone. Thus, while the secondary ion mass spectra do not provide unequivocal support for the presence of hydroxamic acid at the conditioned surface and hence are unable to definitely corroborate the XPS evidence for the co-adsorption of the acid, they are certainly consistent with such co-adsorption.

Secondary ion abundances associated with the major $\mathrm{Cu}$-containing peaks are also listed in Table 1 as a range across the eight $200 \mu \mathrm{m} \times 200 \mu \mathrm{m}$ regions characterised. ${ }^{63} \mathrm{Cu}$-containing positive secondary ion peaks near $m / z 119.95$ and 122.95 were of very low intensity, as they were for bulk $\mathrm{Cu}$ hydroximate. The major secondary ion peaks for conditioned (air-exposed) $\mathrm{Cu}$ metal were the same as those for $\mathrm{Cu}$ hydroximate, despite the fact that for the $\mathrm{Cu}$ metal, very little multilayer Cu hydroximate, as distinct from the monolayer (chemisorbed) collector, would have been present at the solid/vacuum interface. Thus, the diagnostic ions appear to be the same for both the monolayer and Cu hydroximate. 
However, for peak intensities relative to those for $\mathrm{Cu}^{+}$and $\mathrm{Cu}^{-}$, while the abundances of the positive diagnostic secondary ions were consistently lower for the adsorbed layer than for $\mathrm{Cu}$ hydroximate, the abundances of the negative ions were consistently higher for the adsorbed layer (Table 3). Such a clear difference can be rationalised, if not predicted, by recognising that the negative diagnostic $\mathrm{Cu}$-containing ions all contain one or two $\mathrm{O}$ atoms whereas the positive diagnostic ions contain no $\mathrm{O}$ atoms. The spectra indicated that for predominantly a chemisorbed monolayer, $\mathrm{Cu}$-containing ions also including $\mathrm{O}$ were more abundant relative to $\mathrm{Cu}^{-}$, while those not including $\mathrm{O}$ were less abundant relative to $\mathrm{Cu}^{+}$than they were for bulk $\mathrm{Cu}$ hydroximate.

Table 3. Intensities of $\mathrm{Cu}$-containing diagnostic secondary ion peaks from conditioned surfaces of $\mathrm{Cu}$ metal, malachite and pseudomalachite compared with those from bulk $\mathrm{Cu}$ hydroximate (L: lower, $\mathrm{H}$ : higher); for each surface, peak intensities have been normalised relative to the intensities of both $\mathrm{Cu}$ ion and organic fragment ion peaks as in Tables 1 and 4.

\begin{tabular}{ccccccc}
\hline & \multicolumn{5}{c}{ Oxide surface/normalisation } \\
\cline { 2 - 6 } Peak $\boldsymbol{m} / \boldsymbol{z}$ & $\begin{array}{c}\text { Cu metal/ } \\
\text { Cu }\end{array}$ & $\begin{array}{c}\text { Cu metal// } \\
\text { organic }\end{array}$ & $\begin{array}{c}\text { Malachite/ } \\
\mathbf{C u}\end{array}$ & $\begin{array}{c}\text { Malachite/ } \\
\text { organic }\end{array}$ & $\begin{array}{c}\text { Pseudomalachite/ } \\
\mathbf{C u}\end{array}$ & $\begin{array}{c}\text { Pseudomalachite/ } \\
\text { organic }\end{array}$ \\
\hline+90.9 & $23 \% \mathrm{~L}$ & $44 \% \mathrm{~L}$ & $6 \% \mathrm{~L}$ & $39 \% \mathrm{H}$ & $11 \% \mathrm{~L}$ & $17 \% \mathrm{H}$ \\
+104.9 & $39 \% \mathrm{~L}$ & $46 \% \mathrm{~L}$ & $13 \% \mathrm{~L}$ & $43 \% \mathrm{H}$ & $16 \% \mathrm{~L}$ & $17 \% \mathrm{H}$ \\
+118.9 & $40 \% \mathrm{~L}$ & $59 \% \mathrm{~L}$ & $18 \% \mathrm{~L}$ & $29 \% \mathrm{H}$ & $24 \% \mathrm{~L}$ & $11 \% \mathrm{~L}$ \\
-105.9 & $13 \% \mathrm{H}$ & $73 \% \mathrm{~L}$ & $20 \% \mathrm{~L}$ & $57 \% \mathrm{~L}$ & $5 \% \mathrm{~L}$ & $53 \% \mathrm{~L}$ \\
-121.9 & $45 \% \mathrm{H}$ & $72 \% \mathrm{~L}$ & $1 \% \mathrm{H}$ & $55 \% \mathrm{~L}$ & $50 \% \mathrm{H}$ & $39 \% \mathrm{~L}$ \\
-130.9 & $7 \% \mathrm{H}$ & $80 \% \mathrm{~L}$ & $21 \% \mathrm{~L}$ & $63 \% \mathrm{~L}$ & $3 \% \mathrm{~L}$ & $58 \% \mathrm{~L}$ \\
-146.9 & $23 \% \mathrm{H}$ & $77 \% \mathrm{~L}$ & $16 \% \mathrm{~L}$ & $65 \% \mathrm{~L}$ & $8 \% \mathrm{H}$ & $57 \% \mathrm{~L}$ \\
\hline
\end{tabular}

For normalisation by the integrated intensities of the organic secondary ion peaks, both the positive and negative secondary ions were less abundant for the conditioned $\mathrm{Cu}$ metal than for $\mathrm{Cu}$ hydroximate (Table 3). Different abundances for those two specimens would be consistent with the absence of a uniform multilayer of $\mathrm{Cu}$ hydroximate on the conditioned $\mathrm{Cu}$ metal surface. However, it is not immediately obvious whether the particular differences observed indicated a uniform chemisorbed monolayer, patches of chemisorbed monolayer, or patches of chemisorbed monolayer plus physically co-adsorbed hydroxamic acid on the conditioned $\mathrm{Cu}$ metal surface. As noted above, the positive secondary ion spectra were consistent with the presence of co-adsorbed hydroxamic acid, as the peak assigned to the acid parent positive ion (159.126 amu) was of barely detectable intensity for bulk $\mathrm{Cu}$ hydroximate but an order of magnitude greater for the conditioned $\mathrm{Cu}$ metal surface.

Peaks from $\mathrm{CuO}^{-}$and $\mathrm{CuO}_{2}{ }^{-}$were observed, but typically with intensities only $\sim 27 \%$ and $8 \%$, respectively, of the $\mathrm{Cu}^{-}$peaks. These intensities were lower than the normalised values observed for $\mathrm{Cu}$ hydroximate, and hence do not provide support for the possibility that oxidised $\mathrm{Cu}$ not covered by at least a monolayer of collector was a major surface species. Low intensity peaks near $\mathrm{m} / \mathrm{z} 78.94$ and 80.94 from $\mathrm{Cu}$-containing positive secondary ions were observed, but these could be assigned to $\mathrm{CuCH}_{2}{ }^{+}$and there was no evidence for $\mathrm{CuO}_{2}{ }^{+}$ions of appreciable abundance.

As canvassed in Section 2.4, it is the diagnostic secondary ion of highest mass that might be expected to best represent the species present at the surface prior to the primary ion impact. For conditioned oxide $\mathrm{Cu}$ surfaces, it is the negative ion of $\mathrm{m} / \mathrm{z}$ near 146.9 that meets this criterion, and the 
abundance of this ion also happens to be one of the largest of the diagnostic secondary ions. Relative to the $\mathrm{Cu}^{-}$peak intensity, the $\mathrm{m} / z 146.9$ peak was significantly more abundant than for Cu hydroximate, whereas relative to organic fragment peak intensities it was much less abundant than for $\mathrm{Cu}$ hydroximate. One possible interpretation of these observations is that the $\mathrm{Cu}$ metal native oxide was covered predominantly by chemisorbed hydroximate and possibly also co-adsorbed hydroxamic acid rather than multilayer $\mathrm{Cu}$ hydroximate. In other words, there would have been few $\mathrm{Cu}$ atoms at the solid/vacuum interface, so that most of the $\mathrm{Cu}$ atoms ejected would have been those to which the overlying hydroximate had chemisorbed (through its $\mathrm{O}$ atoms) whereas in bulk or multilayer $\mathrm{Cu}$ hydroximate, some $\mathrm{Cu}$ atoms would have been present at the solid/vacuum interface. By contrast, because of the surface excess of chemisorbed hydroximate and co-adsorbed acid, relative to organic fragment secondary ions, $\mathrm{Cu}$-containing fragments would have been less abundant. The positive $\mathrm{Cu}$-containing secondary ions might also be expected to have been relatively less abundant regardless of the normalisation because the positive ions do not contain $\mathrm{O}$, so that only $\mathrm{Cu}$ atoms interacting with the $\mathrm{N}$ of any "horizontally" oriented hydroximate would have contributed to secondary ions that had undergone minimal fragmentation (whereas in bulk $\mathrm{Cu}$ hydroximate essentially all $\mathrm{Cu}$ atoms interact with $\mathrm{N}$ atoms).

In summary, for conditioned $\mathrm{Cu}$ metal, while there is no static SIMS evidence to support a uniform coverage of multilayer $\mathrm{Cu}$ hydroximate or uncovered native oxide, the secondary ion spectra are consistent with monolayer coverage of chemisorbed hydroximate and co-adsorbed hydroxamic acid.

\subsubsection{Conditioned Malachite and Pseudomalachite ToF-SIMS}

The secondary ion mass spectra for the conditioned minerals were not markedly more complicated than those for the bulk $\mathrm{Cu}$ complex, probably because of the presence of multilayer $\mathrm{Cu}$ hydroximate at the mineral/vacuum interface. However, for the pseudomalachite, ${ }^{31} \mathrm{P}^{-}$(30.974 amu) and ${ }^{31} \mathrm{PO}_{2}{ }^{-}$ (62.964 amu) peaks were observed, indicating that some $\mathrm{P}$ would have been near the solid/vacuum interface and consequently that the multilayer $\mathrm{Cu}$ hydroximate would have been in patches. The multilayer might also have been in patches on malachite. For each mineral, the abundance of ${ }^{39} \mathrm{~K}^{+}$ions and ${ }^{40} \mathrm{Ca}^{+}$ions was only slightly greater than for the conditioned $\mathrm{Cu}$ metal surface (Table 4). Peaks from hydroxamic acid ions were of slightly lower intensity than those for the conditioned $\mathrm{Cu}$ metal, consistent with slightly higher co-adsorbed acid on the conditioned $\mathrm{Cu}$ metal. It can be seen from Tables 1 and 4 that the abundances of the $\mathrm{Cu}$-containing diagnostic secondary ions were comparable for both minerals, but somewhat different from those for $\mathrm{Cu}$ hydroximate and the conditioned $\mathrm{Cu}$ metal.

For both minerals, the positive $\mathrm{Cu}$-containing ions were moderately $(\approx 15 \%)$ less abundant than for bulk $\mathrm{Cu}$ hydroximate relative to $\mathrm{Cu}^{+}$ions, but relative to $\mathrm{C}_{5} \mathrm{H}_{11}{ }^{+}$ions, the $\mathrm{Cu}$-containing diagnostic ions were $\approx 35 \%$ more abundant for malachite and $\approx 15 \%$ more abundant for pseudomalachite. These observations would be broadly consistent with patches of adsorbed hydroximate on both minerals (allowing $\mathrm{Cu}$ species other than $\mathrm{Cu}$ hydroximate at the solid/vacuum interface), but fewer or smaller multilayer patches than monolayer patches on pseudomalachite, where a higher concentration of chemisorbed hydroximate relative to multilayer $\mathrm{Cu}$ hydroximate would result in a higher concentration of the organic ligand oriented towards the solid/vacuum interface. 
Table 4. Diagnostic ions and their observed $\mathrm{m} / \mathrm{z}$ and relative abundance ranges for conditioned malachite and pseudomalachite surfaces.

\begin{tabular}{|c|c|c|c|c|c|c|c|}
\hline Ion & $\begin{array}{l}\text { Mass } \\
\text { (amu) }\end{array}$ & $\begin{array}{c}\text { Malachite } \\
\text { observed } \\
m / z \text { range }\end{array}$ & $\begin{array}{c}\text { Malachite } \\
\text { abundance } \\
\text { (rel. Cu) }\end{array}$ & $\begin{array}{c}\text { Malachite } \\
\text { abundance } \\
\text { (rel. } \\
\text { organic) }\end{array}$ & $\begin{array}{c}\text { Pseudo- } \\
\text { malachite } \\
\text { observed } \\
m / \text { z range }\end{array}$ & $\begin{array}{c}\text { Pseudo- } \\
\text { malachite } \\
\text { abundance } \\
\text { (rel. Cu) }\end{array}$ & $\begin{array}{l}\text { Pseudo- } \\
\text { malachite } \\
\text { abundance } \\
\text { (rel. organic) }\end{array}$ \\
\hline${ }^{31} \mathrm{P}$ & 30.974 & - & - & - & $30.969-30.974$ & $0.25 \pm 0.1$ & $0.1 \pm 0.05$ \\
\hline${ }^{39} \mathrm{~K}^{+}$ & 38.9637 & $38.963-38.965$ & $15 \pm 3$ & $12 \pm 6$ & 38.961-38.966 & $22 \pm 6$ & $11.5 \pm 3$ \\
\hline${ }^{40} \mathrm{Ca}^{+}$ & 39.9626 & $39.958-39.961$ & $39 \pm 4$ & $22 \pm 8$ & 39.959-39.965 & $40 \pm 15$ & $18 \pm 6$ \\
\hline${ }^{63} \mathrm{Cu}^{+}$ & 62.9296 & $62.919-62.926$ & 1000 & $550 \pm 160$ & $62.923-62.933$ & 1000 & $485 \pm 90$ \\
\hline $\mathrm{C}_{5} \mathrm{H}_{11}^{+}$ & 71.086 & $71.084-71.090$ & $2 \pm 0.6$ & 1 & $71.087-71.091$ & $2 \pm 0.5$ & 1 \\
\hline $\begin{array}{l}{ }^{63} \mathrm{CuNCH}_{2}{ }^{+} \\
{ }^{63} \mathrm{CuC}_{2} \mathrm{H}_{4}^{+} \\
\end{array}$ & $\begin{array}{l}90.949 \\
90.962 \\
\end{array}$ & $90.951-90.957$ & $44 \pm 2$ & $25 \pm 8$ & $90.953-90.961$ & $42 \pm 3.5$ & $21 \pm 4$ \\
\hline $\begin{array}{l}{ }^{63} \mathrm{CuNC}_{2} \mathrm{H}_{4}^{+} \\
{ }^{63} \mathrm{CuC}_{3} \mathrm{H}_{6}^{+} \\
\end{array}$ & $\begin{array}{l}104.964 \\
104.977 \\
\end{array}$ & $104.963-104.970$ & $8.7 \pm 0.6$ & $5 \pm 1.5$ & $104.967-104.974$ & $8.4 \pm 0.6$ & $4.1 \pm 0.8$ \\
\hline $\begin{array}{l}{ }^{63} \mathrm{CuNC}_{3} \mathrm{H}_{6}^{+} \\
{ }^{63} \mathrm{CuC}_{4} \mathrm{H}_{8}^{+} \\
\end{array}$ & $\begin{array}{l}118.981 \\
118.994 \\
\end{array}$ & $118.973-118.986$ & $7 \pm 1.5$ & $4.5 \pm 1.5$ & $118.982-118.988$ & $6.5 \pm 1$ & $3.1 \pm 0.7$ \\
\hline $\begin{array}{l}\text { (hydroxamic } \\
\text { acid) }^{+}\end{array}$ & 159.126 & $159.148-159.156$ & $2.5 \pm 1.5$ & $2.4 \pm 1.7$ & $159.136-159.156$ & $2 \pm 1.6$ & $1 \pm 0.8$ \\
\hline${ }^{31} \mathrm{P}^{-}$ & 30.974 & - & - & - & $30.972-30.973$ & $3 \pm 2$ & $1 \pm 0.7$ \\
\hline${ }^{63} \mathrm{Cu}^{-}$ & 62.9296 & $62.928-62.933$ & 10 & $3.6 \pm 0.7$ & $62.928-62.931$ & 10 & $4 \pm 1.4$ \\
\hline $\mathrm{PO}_{2}^{-}$ & 62.964 & - & - & - & $62.965-62.967$ & $19 \pm 11$ & $5.6 \pm 2.3$ \\
\hline $\mathrm{C}_{3} \mathrm{H}_{3} \mathrm{O}_{2}^{-}$ & 71.0133 & $71.014-71.021$ & $2.8 \pm 0.5$ & 1 & $71.014-71.023$ & $2.8 \pm 1$ & 1 \\
\hline $\begin{array}{l}{ }^{63} \mathrm{CuONCH}^{-} \\
{ }^{63} \mathrm{CuOC}_{2} \mathrm{H}_{3}{ }^{-}\end{array}$ & $\begin{array}{l}105.935 \\
105.948 \\
\end{array}$ & 105.940-105.949 & $4.8 \pm 0.6$ & $1.9 \pm 0.3$ & $105.943-105.948$ & $5.7 \pm 1.5$ & $2.05 \pm 0.25$ \\
\hline $\begin{array}{l}{ }^{63} \mathrm{CuO}_{2} \mathrm{NCH}^{-} \\
{ }^{63} \mathrm{CuO}_{2} \mathrm{C}_{2} \mathrm{H}_{3}^{-}\end{array}$ & $\begin{array}{l}121.930 \\
121.943 \\
\end{array}$ & $121.936-121.945$ & $10.1 \pm 1.4$ & $3.9 \pm 0.9$ & 121.941-121.947 & $15 \pm 3.5$ & $5.3 \pm 1.2$ \\
\hline $\begin{array}{l}{ }^{63} \mathrm{CuONC}_{3} \mathrm{H}_{2}^{-} \\
{ }^{63} \mathrm{CuOC}_{4} \mathrm{H}_{4}^{-} \\
\end{array}$ & $\begin{array}{l}130.943 \\
130.956 \\
\end{array}$ & $130.936-130.946$ & $5.5 \pm 1$ & $2.2 \pm 0.8$ & $130.942-130.949$ & $6.8 \pm 1$ & $2.5 \pm 0.6$ \\
\hline $\begin{array}{l}{ }^{63} \mathrm{CuO}_{2} \mathrm{NC}_{3} \mathrm{H}_{2}^{-} \\
{ }^{63} \mathrm{CuO}_{2} \mathrm{C}_{4} \mathrm{H}_{4}^{-} \\
\end{array}$ & $\begin{array}{l}146.938 \\
146.951 \\
\end{array}$ & 146.931-146.946 & $21.8 \pm 2.5$ & $8.5 \pm 2$ & $146.940-146.948$ & $28 \pm 5$ & $10.3 \pm 2.2$ \\
\hline $\begin{array}{l}\text { (hydroxamic } \\
\text { acid }-\mathrm{H})^{-}\end{array}$ & 158.118 & $158.119-158.126$ & $0.55 \pm 0.15$ & $0.22 \pm 0.08$ & $158.128-158.139$ & $0.9 \pm 0.2$ & $0.4 \pm 0.1$ \\
\hline
\end{tabular}

Relative to $\mathrm{Cu}^{-}$ions, for malachite the negative $\mathrm{Cu}$-containing ions were moderately less abundant than for $\mathrm{Cu}$ hydroximate, whereas for pseudomalachite they were comparable or even more abundant. Relative to $\mathrm{C}_{3} \mathrm{H}_{3} \mathrm{O}_{2}{ }^{-}$ions, for both minerals the negative $\mathrm{Cu}$-containing ions were appreciably less abundant than for bulk $\mathrm{Cu}$ hydroximate. For the conditioned $\mathrm{Cu}$ metal surface (Section 2.4.1), it was found that relative to $\mathrm{Cu}^{-}$ions, the negative $\mathrm{Cu}$-containing diagnostic ions (which also contain one or two $\mathrm{O}$ atoms) were more abundant than for $\mathrm{Cu}$ hydroximate. These observations can be rationalised by extensive monolayer coverage with multilayer patches on malachite, but not much more than monolayer patches on pseudomalachite. 


\subsubsection{Conditioned Magnetite ToF-SIMS}

Abundant Fe-containing and selected organic fragment secondary ions are listed in Table 2 for comparison with the data for Fe hydroxamate. There was no obvious correlation between the intensity of the $\mathrm{K}^{+}$peak and the intensity of the hydroxamic acid or hydroxamate ion peaks; in fact there was almost an inverse relationship, confirming that the $\mathrm{K}$ that was observed was unlikely to have been from residual collector solution that had not been rinsed from the surface at the end of the conditioning period. Also, there was no obvious correlation between the intensities of the peaks at $\mathrm{m} / \mathrm{z} 38.96$ and 39.96 , so that the peak assigned to $\mathrm{Ca}^{+}$ions (39.963 amu) was unlikely to have arisen instead solely from $\mathrm{KH}^{+}$. However, some of the $m / z 39.96$ peak intensity might have been due to $\mathrm{KH}^{+}$ions (39.972 amu), as otherwise $\mathrm{Ca}^{+}$ions would have been more abundant than expected. For the conditioned magnetite, (hydroxamic acid) ${ }^{+}$ions were relatively abundant (compared with not observed for Fe hydroxamate), but the (acid) ${ }^{-}$and (acid $\left.-\mathrm{H}\right)^{-}$abundances were comparable with those for Fe hydroxamate. As for $\mathrm{Fe}$ hydroxamate, $\mathrm{FeH}^{-}$ions were more abundant that $\mathrm{Fe}^{-}$, unlike the relative abundance of $\mathrm{CuH}^{-}$and $\mathrm{Cu}^{-}$for the analogous conditioned oxide $\mathrm{Cu}$ surfaces. As for conditioned oxide $\mathrm{Cu}$ surfaces, there was no clear indication that the metal-containing diagnostic ions also contained $\mathrm{N}$ rather than $\mathrm{CH}_{2}$ or vice versa.

Differences in the Fe-containing diagnostic ion abundances for the conditioned magnetite surface relative to those for Fe hydroxamate are listed in Table 5. It can be seen that the difference in abundance for each positive diagnostic ion is in fairly close agreement regardless of whether the peak intensities had been normalised by the $\mathrm{Fe}^{+}$or $\mathrm{C}_{4} \mathrm{H}_{9}{ }^{+}$peak intensities. With one exception, the difference for each negative diagnostic ion is also in close agreement for normalisation by $\mathrm{FeH}^{-}$or $\mathrm{O}_{2} \mathrm{C}_{2} \mathrm{H}_{2}^{-}$peak intensities.

Table 5. Intensities of Fe-containing diagnostic secondary ion peaks from conditioned magnetite surfaces compared with those from bulk Fe hydroxamate (L: lower, H: higher); peak intensities have been normalised relative to the intensities of both Fe ion and organic fragment ion peaks as in Table 2 .

\begin{tabular}{ccc}
\hline \multirow{2}{*}{ Peak $\boldsymbol{m} / \boldsymbol{z}$} & \multicolumn{2}{c}{ Normalisation } \\
\cline { 2 - 3 } & Fe & Organic \\
\hline+70.9 & $60 \% \mathrm{~L}$ & $41 \% \mathrm{~L}$ \\
+84.9 & $15 \% \mathrm{~L}$ & $10 \% \mathrm{~L}$ \\
+96.9 & $2 \% \mathrm{H}$ & $1 \% \mathrm{~L}$ \\
+112.9 & $41 \% \mathrm{~L}$ & $37 \% \mathrm{~L}$ \\
+115.9 & $83 \% \mathrm{~L}$ & $81 \% \mathrm{~L}$ \\
-98.9 & $77 \% \mathrm{~L}$ & $90 \% \mathrm{~L}$ \\
-113.9 & $87 \% \mathrm{~L}$ & $94 \% \mathrm{~L}$ \\
-114.9 & $90 \% \mathrm{~L}$ & $54 \% \mathrm{~L}$ \\
-139.9 & $94 \% \mathrm{~L}$ & $98 \% \mathrm{~L}$ \\
\hline
\end{tabular}

The mid-range $m / z$ Fe-containing positive diagnostic ions were of comparable abundance to those of bulk Fe hydroxamate, but the lower and higher $\mathrm{m} / \mathrm{z}$ positive, and all the negative, diagnostic ions were up to an order of magnitude lower than for bulk Fe hydroxamate. Therefore, the secondary ion 
spectra indicated that the adsorbate on magnetite could not have been similar to a uniform $\mathrm{Fe}$ hydroxamate multilayer, but they were consistent with no greater than monolayer coverage or possibly sparse patches of multilayer Fe hydroxamate.

It might have been expected that $\mathrm{FeO}_{x}(\mathrm{NCH})$ ions (where $x>4$ ) would be more abundant for bulk Fe hydroxamate than for the adsorbed hydroxamate monolayer. For bulk Fe hydroxamate, relatively intense peaks attributable to ions such as ${ }^{56} \mathrm{FeO}_{5} \mathrm{NC}_{3} \mathrm{H}^{-},{ }^{56} \mathrm{FeO}_{6} \mathrm{NC}^{-}$and ${ }^{56} \mathrm{FeO}_{6} \mathrm{NC}_{3} \mathrm{H}^{-}$were observed with abundances $\sim 45,30$ and 155, respectively, normalised by the $\mathrm{FeH}^{-}$intensity, whereas for conditioned magnetite the corresponding values were less than $1,1.5$ and 2.5.

\section{Experimental Details}

\subsection{Materials and Surfaces Characterised}

Cupric hydroximate, $\mathrm{Cu}\left(\mathrm{O}_{2} \mathrm{CNC}_{7} \mathrm{H}_{15}\right)$, was prepared by the addition of an aqueous $\mathrm{Cu}$ sulfate solution to a nominally saturated aqueous solution of potassium hydrogen $n$-octanohydroxamate, and the precipitated complex washed thoroughly with distilled water. The ferric hydroxamate, $\mathrm{Fe}\left(\mathrm{O}_{2} \mathrm{CNHC}_{7} \mathrm{H}_{15}\right)_{3}$, was prepared as described previously [3].

After being freshly abraded in air, surfaces of $\mathrm{Cu}$ metal, malachite from Morocco, pseudomalachite from Tottenham, NSW, Australia and magnetite from Mineville, NY, USA were conditioned in a nominally saturated $(\sim 0.02 \mathrm{M})$ aqueous solution of potassium hydrogen $n$-octanohydroxamate at its unadjusted $\mathrm{pH}$ ( $\sim 9.5$ ) for $2 \mathrm{~min}$ (Cu systems) or $5 \mathrm{~min}$ (magnetite). Following the conditioning period, the surfaces were rinsed thoroughly with distilled water and dried under a stream if nitrogen. In each case, the conditioned surface appeared to be hydrophobic, so that retention of any weakly adhering collector solution should not have been a problem.

\subsection{X-ray Photoelectron Spectroscopy}

$\mathrm{X}$-ray photoelectron spectra were collected from $\mathrm{Cu}$ hydroximate and $\mathrm{Fe}$ hydroxamate powder pressed into the surface of freshly exposed indium, and from conditioned single piece specimens of $\mathrm{Cu}$ metal, malachite and pseudomalachite of size approximately $5 \mathrm{~mm} \times 5 \mathrm{~mm} \times 1 \mathrm{~mm}$. Each Cu metal or mineral surface, that had been abraded until relatively smooth to the unaided eye, was rinsed with pure water at its unadjusted $\mathrm{pH}$ after conditioning in collector solution and before characterisation by XPS at ambient temperature.

XPS data were obtained on an ESCALAB 250Xi spectrometer located within the UNSW Analytical Centre using monochromatised $\mathrm{Al} \mathrm{K}_{\alpha} \mathrm{X}$-rays focused to a spot size of $0.5 \mathrm{~mm}$ and an electron analyser pass energy of $20 \mathrm{eV}$ for narrow range scans. Included in the binding energies employed for calibration were $83.96 \mathrm{eV}$ for $\mathrm{Au} 4 f_{7 / 2}$ of metallic gold and $932.6 \mathrm{eV}$ for $\mathrm{Cu} 2 \mathrm{p}_{3 / 2}$ of $\mathrm{Cu}$ metal. The pressure in the analysis chamber was better than $5 \times 10^{-9}$ mbar during spectral acquisition. The data were collected and processed under Thermo Scientific Avantage 4.58 and 4.54 software.

Because of the low conductivity of the bulk complexes and $\mathrm{Cu}$ minerals, their spectra were obtained under the influence of low energy electrons from an in-lens flood-gun. In minimising peak broadening from a non-uniform potential within the specimen surface layer, the low energy electrons "over-compensate" for charging and the measured photoelectron binding energies are typically lower 
than their correct energies by a value approaching the energy of the electrons $(\sim 4.6 \mathrm{eV})$. The measured binding energies are corrected by assuming that they will all be affected by the same energy, and adjusting them so that the hydrocarbon $\mathrm{C} 1 \mathrm{~s}$ binding energy is $285.0 \mathrm{eV}$. Whenever the flood-gun was used, the possibility of beam damage or alteration by the low energy electrons was monitored. In particular, N 1s spectra were obtained at the outset and again at the end of the spectral suite to quantify the extent of any alteration. However, in all cases, spectra were obtained as quickly as possible, at the expense of signal-to-noise, in order to minimise any damage arising from the secondary electrons associated with the X-ray photoemission. The magnetic lens mode of the analyser was used in all cases, so that the core of the flood-gun electron beam would have been of less than $1 \mathrm{~mm}$ diameter with the tail extending to no more than $3 \mathrm{~mm}$ diameter. When several specimens were mounted on the same stub, they were separated by more than $1 \mathrm{~cm}$. Spectra from the conditioned $\mathrm{Cu}$ metal and magnetite were obtained without the need for a flood-gun.

\subsection{Static SIMS}

The static SIMS data were obtained using $30 \mathrm{keV} \mathrm{Au}^{+}$primary ions in a PHI TRIFT V nanoTOF spectrometer located at the IWRI, University of South Australia. For each region analysed, the pulsed $0.5 \mathrm{nA}$ primary ion beam from a liquid metal ion gun was rastered over a $200 \mu \mathrm{m} \times 200 \mu \mathrm{m}$ area to provide an ion dose no greater than $2.5 \times 10^{11}$ ions $\mathrm{cm}^{-2}$. Secondary ions were accumulated for a period of $1 \mathrm{~min}$ with a $100 \mu \mathrm{m}$ aperture at an $\mathrm{m} / \mathrm{z}$ resolution of $\sim 8000$. Dual charge neutralisation was effected by an interlaced pulsed beam of $10 \mathrm{eV}$ electrons and $10 \mathrm{eV} \mathrm{Ar}^{+}$ions. Secondary ion spectra were obtained and processed under WinCadenceN version 1.8.1.3 software.

Calibration of the $\mathrm{m} / \mathrm{z}$ scale was particularly important in this investigation as differentiation of species containing $\mathrm{N}$ (mass 14.003) or $\mathrm{CH}_{2}$ (mass 14.016) was sought. Such a difference in mass would not be an issue with electron ionised vapour phase mass spectrometers, but is marginal with static SIMS [15]. For calibration of the $m / z$ scale, peaks from $\mathrm{CH}_{3}{ }^{+}, \mathrm{C}_{2} \mathrm{H}_{5}{ }^{+}$and $\mathrm{C}_{3} \mathrm{H}_{7}{ }^{+}$or $\mathrm{CH}^{-}, \mathrm{C}_{2} \mathrm{H}^{-}$ and extraneous $\mathrm{Cl}^{-}$ions were used in positive or negative mode, respectively, and checked with peaks from $\mathrm{C}_{4} \mathrm{H}_{9}{ }^{+}$and $\mathrm{O}_{2} \mathrm{C}_{2} \mathrm{H}_{2}{ }^{-}$. Peaks from $\mathrm{C}_{4} \mathrm{H}_{9}{ }^{+}$(57.070), $\mathrm{C}_{5} \mathrm{H}_{7}{ }^{+}$(67.055), $\mathrm{C}_{5} \mathrm{H}_{9}{ }^{+}$(69.070) and $\mathrm{C}_{6} \mathrm{H}_{5}{ }^{+}$(77.039) ions were observed within 2, 3, 1 and 9 mamu, respectively, of the expected values. Positive secondary ion integrated peak intensities were normalised by the intensities of peaks from $\mathrm{Cu}^{+}$ and $\mathrm{C}_{5} \mathrm{H}_{11}{ }^{+}$for $\mathrm{Cu}$ systems or $\mathrm{Fe}^{+}$and $\mathrm{C}_{4} \mathrm{H}_{9}{ }^{+}$for $\mathrm{Fe}$ hydroxamate and magnetite. Negative secondary ion peak intensities were normalised by the intensities of peaks from $\mathrm{Cu}^{-}$and $\mathrm{O}_{2} \mathrm{C}_{3} \mathrm{H}_{3}{ }^{-}$for $\mathrm{Cu}$ systems or $\mathrm{FeH}^{-}$and $\mathrm{O}_{2} \mathrm{C}_{2} \mathrm{H}_{2}{ }^{-}$for $\mathrm{Fe}$ hydroxamate and magnetite.

For calibration of the mass scale, it is generally accepted that either all inorganic or all organic secondary ions should be used, and with the latter, it is better to avoid the inclusion of ions that would have undergone significant rearrangement. If molecular ions are of primary interest, it is contended that it is better not to use atomic ions in the calibration procedure. Other difficulties typically encountered in determining an accurate $\mathrm{m} / \mathrm{z}$ value for a secondary ion in ToF-SIMS have been discussed by Green et al. [15]. Included in those problems for specimens with a surface that is rough on the atomic scale is that small differences in specimen height can result in significant differences in time-of-flight for a secondary ion species. As the aperture is decreased, peak shape improves considerably but the intensity decreases; while the shape of a secondary ion peak is important, 
adequate intensity is required for determining a precise $\mathrm{m} / \mathrm{z}$ value. All these measurement difficulties are in addition to the fundamental issue of whether a significant proportion of secondary ions reflect the species present at the surface prior to impact by the primary ion.

\section{Conclusions}

Related sets of diagnostic metal-containing secondary ions were identified for bulk $\mathrm{Cu}$ hydroximate and $\mathrm{Fe}$ hydroxamate. The most abundant $\mathrm{Cu}$-containing positive ions for $\mathrm{Cu}$ hydroximate did not also contain $\mathrm{O}$, whereas the most abundant Fe-containing positive ions for Fe hydroxamate did contain $\mathrm{O}$. The most abundant negative $\mathrm{Cu}$-containing ions all contained at least one $\mathrm{O}$ atom. The $\mathrm{Cu}$ analogs of the largest, abundant, Fe-containing positive ions observed for $\mathrm{Fe}$ hydroxamate were of very low abundance for $\mathrm{Cu}$ hydroximate. Apart from that difference in metal-containing positive ions, there was no obvious difference in the organic structure of those ions from the two bulk complexes. In particular, the smaller, abundant Fe-containing positive ions also contained either $\mathrm{N}$ or $\mathrm{CH}_{2}$, but not $\mathrm{O}$. In other words, the most abundant fragment secondary ions did not clearly distinguish between the different bonding arrangements in the $\mathrm{Cu}$ and $\mathrm{Fe}$ complexes expected from spectroscopic and solubility data, and therefore did not corroborate the structures deduced from XPS and vibrational spectroscopy. Because of the different structures of the two complexes, it might have been expected that secondary ions containing $\mathrm{Cu}$ and $\mathrm{N}$ but no $\mathrm{O}$ would have been observed, whereas ions containing $\mathrm{Fe}$ and $\mathrm{N}$ without $\mathrm{O}$ should not have been abundant unless rearrangement prior to ion ejection had occurred.

Distinguishing ions containing $\mathrm{N}$ from those containing $\mathrm{CH}_{2}$ was not as straightforward as might have been expected given the high spectral resolution, principally because of the uncertainty in determining $\mathrm{m} / \mathrm{z}$ values outside the range that could be calibrated reliably, and the specimen surface roughness at the microscopic level. Notwithstanding this uncertainty, for the negative $\mathrm{Cu}$-containing secondary ions in particular, assignment of the observed diagnostic peak to the $\mathrm{N}$ rather than $\mathrm{CH}_{2}$ species appeared to be justified. However, the analogous Fe-containing negative ions from $\mathrm{Fe}$ hydroxamate also appeared to be the $\mathrm{N}$ rather than $\mathrm{CH}_{2}$ species. Therefore, it would appear that these secondary ions do not necessarily reflect the structure, especially the different $\mathrm{N}$ bonding arrangement, prior to impact by the primary ions. Nevertheless, the abundant secondary ions were consistent with the number of oxygen nearest neighbours in the two complexes, and they should also be diagnostic secondary ions for multilayer $\mathrm{Cu}$ hydroximate or $\mathrm{Fe}$ hydroxamate adsorbed on oxide $\mathrm{Cu}$ or Fe minerals.

For the conditioned oxide $\mathrm{Cu}$ surfaces, the photoelectron and secondary ion mass spectra were in agreement as far as collector coverage was concerned. The diagnostic ions appeared to be the same for both the monolayer adsorbed on air-exposed $\mathrm{Cu}$ metal and for $\mathrm{Cu}$ hydroximate. However, for peak intensities relative to those for $\mathrm{Cu}^{+}$or $\mathrm{Cu}^{-}$, while the abundances of the positive diagnostic secondary ions were consistently lower for the adsorbed layer than for $\mathrm{Cu}$ hydroximate, the abundances of the negative ions were consistently higher for the adsorbed layer. The positive secondary ion spectra were consistent with the presence of co-adsorbed hydroxamic acid. For collector coverage on conditioned magnetite too, the static SIMS and XPS data were in agreement. The secondary ion spectra indicated that the adsorbate was certainly different from a uniform Fe hydroxamate multilayer, and were consistent with no greater than monolayer coverage or possibly sparse patches of multilayer Fe hydroxamate. 
Although it proved too difficult to obtain sufficiently reliable $\mathrm{m} / \mathrm{z}$ values for the larger diagnostic secondary ions, that would have been more likely to reflect the surface chemical structure prior to primary ion impact, static SIMS can provide useful additional information to complement XPS data for hydroxamate conditioned oxide mineral surfaces. When compared with the abundances of the metal-containing secondary ions for the bulk complexes, the relative abundances of those diagnostic ions for the conditioned mineral surfaces varied with, and could be rationalised by, the monolayer or multilayer coverage of the adsorbed collector. Furthermore, parent secondary ions were able to provide supporting information on the co-adsorption of hydroxamic acid at each conditioned surface. Nevertheless, while the secondary ion spectra complemented the XPS data, they would not have been able to provide stand-alone information as an alternative to the photoelectron spectra.

\section{Acknowledgments}

This research was supported under the Australian Research Council's Linkage Project funding scheme (project No. LP 0990404) with industry partner Australian Metallurgical Services Pty Ltd. (established by Axis House). The authors acknowledge the assistance of the AMMRF at the South Australian Regional Facility, University of South Australia, a facility funded by the University, and State and Federal Governments. The authors are grateful to Craig Klauber (CSIRO) for the sample of magnetite and to Bill Gong (UNSW Analytical Centre) for assistance in obtaining the XPS data.

\section{References}

1. Hope, G.A.; Woods, R.; Buckley, A.N.; White, J.M.; McLean, J. Spectroscopic characterisation of n-octanohydroxamic acid and potassium hydrogen n-octanohydroxamate. Inorg. Chim. Acta 2010, 363, 935-943.

2. Liu, W.; Wang, B.; Dai, S.; Ma, A.; Wei, D. Current application and development prospect of hydroxamic acid in flotation. Non-Ferr. Min. Metall. 2006, 22, 25-27.

3. Parker, G.K.; Hope, G.A.; Woods, R.; Numprasanthai, A.; Buckley, A.N.; McLean, J. Investigation of $n$-octanohydroxamate reagent interaction with the surface of oxide copper minerals and copper metal. In Separation Technologies for Minerals, Coal, and Earth Resources; Young, C.A., Luttrell, G.H., Eds.; SME Inc.: Englewood, CO, USA, 2012; pp. 497-508.

4. Parker, G.K.; Buckley, A.N.; Woods, R.; Hope, G.A. The interaction of the flotation reagent, n-octanohydroxamate, with sulfide minerals. Miner. Eng. 2012, 36-38, 81-90.

5. Cui, J.; Hope, G.A.; Buckley, A.N. Spectroscopic investigation of the interaction of hydroxamate with bastnaesite (cerium) and rare earth oxides. Miner. Eng. 2012, 36-38, 91-99.

6. Vickerman, J.C. Molecular SIMS - A journey from single crystal to biological surface studies. Surf. Sci. 2009, 603, 1926-1936.

7. Goh, S.W.; Buckley, A.N.; Lamb, R.N.; Woods, R. The ability of static secondary ion mass spectrometry to discriminate submonolayer from multilayer adsorption of thiol collectors. Miner. Eng. 2006, 19, 571-581.

8. Hope, G.A.; Woods, R.; Parker, G.K.; Buckley, A.N.; McLean, J. Spectroscopic characterisation of copper acetohydroxamate and copper n-octanohydroxamate. Inorg. Chim. Acta 2011, 365, 65-70. 
9. Folkers, J.P.; Gorman, C.B.; Laibinis, P.E.; Buchholz, S.; Whitesides, G.M.; Nuzzo, R.G. Self-assembled monolayers of long-chain hydroxamic acids on the native oxides of metals. Langmuir 1995, 11, 813-824.

10. Keszthelyi, T.; Paszti, Z.; Rigo, T.; Hakkel, O.; Telegdi, J.; Guczi, L. Investigation of solid surfaces modified by Langmuir-Blodgett monolayers using sum-frequency vibrational spectroscopy and X-ray photoelectron spectroscopy. J. Phys. Chem. B 2006, 110, 8701-8714.

11. Failes, T.W.; Hambley, T.W. Crystal structures of tris(hydroxamato) complexes of iron(III). Aust. J. Chem. 2000, 53, 879-881.

12. Hope, G.A.; Buckley, A.N.; Parker, G.K.; Numprasanthi, A.; Woods, R.; McLean, J. The interaction of $n$-octanohydroxamate with chrysocolla and oxide copper surfaces. Miner. Eng. 2012, 36-38, 2-11.

13. Fuerstenau, D.W.; Pradip. Mineral flotation with hydroxamate collectors. In Reagents in the Minerals Industry; Jones, M.J., Oblatt, R., Eds.; Institution of Mining Metallurgy: London, UK, 1984; pp. 161-168.

14. King, A.; Henkel, T.; Rost, D.; Lyon, I.C. Determination of relative sensitivity factors during secondary ion sputtering of silicate glasses by $\mathrm{Au}^{+}, \mathrm{Au}_{2}{ }^{+}$and $\mathrm{Au}_{3}{ }^{+}$ions. Rapid Commun. Mass Spectrom. 2010, 24, 15-20.

15. Green, F.M.; Gilmore, I.S.; Seah, M.P. TOF-SIMS: Accurate mass scale calibration. J. Am. Soc. Mass Spectrom. 2006, 17, 514-523.

(C) 2012 by the authors; licensee MDPI, Basel, Switzerland. This article is an open access article distributed under the terms and conditions of the Creative Commons Attribution license (http://creativecommons.org/licenses/by/3.0/). 